\title{
Análisis teológico pastoral de la Iglesia latinoamericana
}

\author{
Pedro Trigo, \\ Centro Gumilla, \\ Caracas, Venezuela.
}

\section{Proyectos pastorales de la Iglesia latinoamericana}

Resulta patente la variedad, por ahora incomponible, de las expresiones teóricas, simbólicas, éticas y polf́ticas del cristianismo latinoamericano. Explicar la diversidad por la distinción entre la vanguardia y las masas, o el alto y el bajo clero, o los clérigos y los laicos, o las congregaciones religiosas y el clero secular, o la generación de antes del Concilio y la que se formo después... no resiste un riguroso análisis. El origen de clase de los miembros de la institución eclesiástica o el medio en el que desarrollan su actividad, o el tipo de formación que recibieron, son, sin duda, factores que influyen, pero que por sl mismos están muy lejos de explicar la diversidad que llega, incluso, a contradicciones antagónicas en sus planteamientos y posiciones.

No queremos negar con esto la existencia de la Iglesia latinoamericana como un todo. Existe esa Iglesia latinoamericana: cada quien habla en ella y desde ella toma sus posiciones y se reconoce en su seno. La III Conferencia General del Episcopado en Puebla a (1977) es la prueba más palmaria de la irrenunciable voluntad de comunión de los católicos latinoamericanos. Pero también allí se evidencia que la comunión no es posible como uniformidad, sino en el pluralismo, en el diálogo, incluso en la confrontación. ${ }^{1} \mathrm{La}$ unidad de la Iglesia latinoamericana se da en el origen, en la voluntad de comunión, en el reconocimiento mutuo y en el reino de Dios como mela efectivamente perseguida.

En la Iglesia latinoamericana, así entendida como conjunto, operan hoy tres proyecios pastorales. No se diferencian por los métodos o las insistencias a partir de conceptos unívocos. Cada proyecto mantiene su propia comprensión de los conceptos fundamentales, de forma tal que no son, sin más homologables. Es decir, los conceptos de Dios, Jesús, salvación, Iglesia, pecado, hombre, mundo, sociedad, no son, ni mucho menos unívocos. De allí que el mundo-de-vida de los cristianos encuadrados en cada uno de esos proyectos ofrezca un talante distinto.

Pero el panorama se amplía más aún si tomamos en cuenta que estos tres proyectos no encuadran a la totalidad de los que hoy en América Latina se autode- 
nominan cristianos. Más aún, la mayoría ha sido de algún modo afectada por ellos, pero se mantiene todavla en una comprensión y vivencia cristianas anteriores a cualquiera de los proyectos. Viven todavía en lo que designaríamos técnicamente como cristiondad latinoamericana. Esta viene a ser de este modo la base sobre la que actúan los tres proyectos a los que vamos a hacer referencia. Pero, considerada en sí misma, no es una materia pasiva dispuesta para ser exteriormente moldeada. Es una forma activa que, aunque presenta signos de desintegración, se muestra capaz de reproducirse a si misma y sobrevivir. ${ }^{2}$

\section{La cristiandad colonial ${ }^{3}$}

Llamamos cristiandad a una elapa historica del cristianismo que viene caracterizada por la común e indivisa pertenencia a una comunidad étnica, política y religiosa. La cristiandad no es sólo uno de los aspectos o de los componentes de la formación de América Latina, sino precisamente su justificación ideológica y su condición de posibilidad. A lo largo del siglo XIX se resquebrajó el régimen de cristiandad. Pero en todos los sectores sociales aún subsisten muchos de sus elementos; más, por supuesto, en los sectores tradicionales y en las clases populares.

Si no la historia, sí la vida individual y social está aún pautada por ritos cristianos. A nivel individual los ritos de pasaje (nacimiento, pubertad, matrimonio, muerte) aún revisten para muchos un carácter sagrado y una simbolización cristiana (bautismo, primera comunión, matrimonio eclesiástico, exequias). Lo mismo sucede a nivel local con las fiestas estacionales (sobre todo los ciclos de navidad y semana santa) y las de afirmación de la comunidad ancestral (el santo patrón). Y otro tanto podemos decir de las fiestas nacionales. Así, pues, hoy en América Latina tanto los individuos como las colectividades se socializan y autoafirman en buena medida mediante los ritos cristianos. Y no sólo eso, las celebraciones patrias, o los eventos deportivos, económicos, etc., incluyen normalmente en su celebración algún componente religioso, expresado en el ritual cristiano: bendiciones, $T e$ Deum, misa, peLición o acción de gracias...

Naturalmente que esta tupida trama de ritos supone, más o menos consciente, pero siempre presente y actuante, una cierla visión del mundo y del puesto del hombre en él, de su origen, de su destino y del modo de alcanzarlo. Todo esto se plasma en los ritos, más de un modo intuitivo que conceptual. Pero, sin duda, tiene otras muchas expresiones. Podemos decir, de un modo general, que los hombres y colectividades asumen la cristiandad como una realidad ancestral, con todo lo que de genuino y de paradigmático tiene, pero también con todo lo que lo tradicional tiene de lejano a causa de los cambios culturales repentinos e inmanejables.

La consecuencia de esto es no sólo la permanencia pública de los símbolos, sino la relevancia social de los personajes de la institución eclesiástica, de los ministros sagrados, que aparecen en los actos públicos formando parte de las figurass representativas y de las fuerzas vivas. Esta relevancia se debe a la capacidad que aún conserva la institución eclesiástica de representar un consenso difuso, pero básico en 
cuanto ministros legitimos y reconocidos del cristianismo que todavía configura a nuestro subcontinente como totalidad. No se trata de una supervivencia, sino de un potencial vivo y disponible.

\section{Restauración de la cristiandad4}

Sobre esta cristiandad actúan en nuestro siglo hasta hoy tres proyectos historicos: El primero, inducido desde Roma, encontró sin embargo el campo abonado en la instiución eclesiástica latinoamericana. Su objetivo es restouror la cristiandad colonial con los cambios imprescindibles para hacerla viable. El segundo, traído a América Latina por élites católicas en contacto con la renovación católica europea, abandona el paradigma colonial y propone instaurar una nueva cristiandad, ya no sacral, sino secular. El tercero, genuinamente latinoamericano, se propone la liberación integral de nuestro pueblo creyente y oprimido para que reluzca la fraternidad que ya los primeros evangelizadores inculcaron en el ethos élico-mítico constituyente de América Latina.

\subsection{Diagnóstico y proposiciones}

En primer lugar, el proyecto de restauración de la cristiandad. Deriva de la alianza entre el trono y el altar sellada en el Congreso de Viena (1814) tras la derrota de Napoleón. Pero, en America Latina se instrumentó en gran escala y con un plan preciso a partir del Primer Concilio Plenario Latinoamericano, que reunió a los obispos del continente en Roma en 1899.5 El diagnóstico que estableció dicho concilio sobre la cristiandad latinoamericana percibe a ésta como en estado de debilidad interior y externamente amenazada. La debilidad se debla a la ignorancia religiosa del pueblo y a la poca oportunidad que tienen de alimentarse con las devociones y el culto. La amenaza extema provenía de los "enemigos de la fe." Estos se encuentran en las élites, separadas simultáneamente del pueblo y de la Iglesia. Desprecian a ambos porque los miran desde la modemidad, que es a la vez secularización y extranjerismo.

Para los obispos del Concilio Plenario, la cristiandad latinoamericana, con su sacralidad omnipresente, seguía siendo una referencia ideal y, por eso, como objetivo de su proyecto pastoral, se propusieron restaurarla. Para acabar con la ignorancia religiosa se necesitaba catecismo, para alimentar la vida cristiana era preciso reavivar el culto, para responder a los "errores" modernos se regularia la instrucción cristiana de la juventud; y para poner a salvo a los fieles de ese mundo moderno que se levantaba al margen de la institución eclesiástica había que crear instituciones confesionales.

Si el pueblo era "menor de edad" y las élites estaban enajenadas, sólo la institución eclesiástica podía llevar adelante el proyecto. Además ella era el ministro autorizado de lo sacral. La institución eclesiástica, y sobre todo el clero, será, por consiguiente, el sujeto histórico del proyecto de restauración de la cristiandad. Pero, el clero era lo que más escaseaba. De allí que la prioridad del proyecto sean los seminarios: un seminario menor en cada diócesis, un seminario mayor en cada región. Pero, no se trataba sólo de aumentar el número, sino de imbuirlos de las perspectivas 
del proyecto y dotarlos de la capacidad para llevarlo a cabo. De ahf, la insistencia en la neo-escolástica como esquema mental, en el derecho canónico como disciplina y en una espiritualidad fuertemente ascética, por un lado, pero sentimental por el otro.

\subsection{Análisis del Concilio Plenario}

\subsubsection{Por qué la institución eclesiástica pacta con el Estado}

El concilio parte de una acentrada conciencia de sí: "Desde su conversión nada se ha hecho en toda América Latina que supere en esplendor, magnificiencia y abundancia de gracias a la solemne celebración del Concilio Plenario" (Acta et Decreta Concilii Plenarii Americae Latinae. Typis Vaticanis MDCCCC, p. XCVI-VII).

Cada página del concilio atestigua por una parte la hostilidad del medio y la correlación de fuerzas netamente desfavorable, por el momento; pero atestigua con más fuerza si cabe el convencimiento absoluto en la propia posición y la fe en que la situación actual va a ser sobrepasada. Es un concilio militante, consciente de la gravedad del momento, pero no menos consciente de que se dirige a una institución disciplinada y a un pueblo fiel. De ahí el aplomo en medio del estremecimiento.

Los 16 útulos de que consta se dirigen unánimemente a lograr aquello para lo que León XIII lo convoco: "para que se mantuviese a salvo la unidad de la disciplina eclesiástica" (XIV). En ellos aparece claro que el sujeto de este proyecto pastoral es la institución eclesiástica; ella sería por antonomasia la Iglesia. Y de su existencia vigorosa depende el florecimiento del cristianismo y la salvación de las gentes.

Basándose en la Inmortale Dei y en el Syllabus, se rechaza la pretensión de la autoridad civil de entrometerse en los asuntos eclesiásticos (número 91-95) y se afirma el derecho de la Iglesia de adquirir y poseer bienes temporales (824-848). Se condena la separación entre la Iglesia y el Estado y se estimula la mutua concordia $(103,106,763 \ldots)$ ya que "es utilísimo al gobiemo civil proteger los derechos de la Iglesia y ayudarla; ya que de ahí le viene al gobiemo mayor potestad y estabilidad" (737). Por eso se pide insistentemente a los escritores católicos que "eviten lo que pueda exacerbar a los que en el presente dirigen la administración pública" (739).

La Iglesia, extenuada por las convulsiones del siglo XIX, busca no sólo la concordia sino el surgimiento de gobernantes cristianos con quicnes restaurar de nuevo el régimen de cristiandad. Por eso afirma su derecho divino y la utilidad de su apoyo y propone la alianza: por parte del Eslado, privilegio; por parte de la Iglesia, estabilización del Estado.

A pesar de todas las resistencias del ambiente intelectual y político, los gobernantes captaron la conveniencia de este pacto y, aun en el caso de México, con una u otra fórmula, con el tiempe acabarán aceptándolo.

\subsubsection{Institucionalización paralela}

En este marco público el concilio plantea una lucha idcológica total. Los enemigos son "los errores de nuestro tiempo:" el ateísmo (99), el materialismo, el 
evolucionismo (100), el panteísmo, el racionalismo (102), el naturalismo (103), el indiferentismo (108) y, destacados de un modo especial por su incidencia y peligrosidad, el liberalismo (104-105), el positivismo, al que serian particularmente proclives los médicos (103) y el protestantismo (110).

Eslos errores se difunden en la prensa, en las revistas y en los libros, muchos de los cuales propugnan, dicen, "el así llamado volterianismo" (130) y se infiltran especialmente en las novelas (132) cuya lectura se prohibe severamente. Pcro su plataforma de difusión es sobre todo la educación. Por eso se condenan sin apelación las "escuelas llamadas neutras, mixtas o laicas" (135-138), lo mismo que el laicismo de la educación media o superior (139). Se manda a los padres "con toda la autoridad que poseemos" que aparten a sus hijos de las escuelas que no estén bajo el influjo de la Iglesia (677). Incluso se restringe severamente el trato con los acatólicos (143149).

El mundo está perdido y es necesario edificar desde sus cimientos una sociedad nueva. De ahl la meticulosa programación de una institucionalización paralela en todos los órdenes de la vida: en el de la convivencia ordinaria y la recreación, en el de la educación, en el laboral y en el políico.

El pilar del proyecto es sin duda la educación católica. Y ante todo la primaria (673-685). En cada parroquia, una escuela parroquial (676). Con toda la severidad de las penas canónicas se manda a los párrocos que la implanten (678) y que la conserven (679) y al obispo que la inspeccione detenidamente. A los padres se les obliga que manden a sus hijos a las escuelas parroquiales o a otras reconocidas por el obispo como catolicas (677). Pero como las escuelas católicas no pueden funcionar con eficacia si no se forman maestros escogidos y con firmes convicciones, urgen la constutución de escuelas normales (684). Los religiosos dedicados a la enseflanza se encargarán de esta tarea (id).

Sobre esta base de la escuela católica, se enfrentan al problema de la educación media. La educación estatal, de carácter laico, les parece sumamente peligrosa y por eso planean el fomento de la secundaria católica (686-691). Recuerdan a los padres la "gravísima obligación" que pesa sobre ellos de preferir los centros católicos a los demás (686). Al comprobar cómo se extiende la educación femenina, insisten en la creación de colegios para muchachas (690); pero prohíben de un modo tajante la educación mixta (id).

Reglamentan los ejercicios de piedad que han de tener los colegios católicos y que en efecto tuvieron hasla mediados de los años 60, por lo menos (690).

Este circuito educativo se corona en la universidad. De ahí que, a pesar de la situación de precariedad absoluta o incluso de persecución en que se encontraban, decreten, sin embargo, con absoluta confianza en el futuro: "que cada república o región de América Latina tenga su universidad católica" (696).

En estos ámbitos de la educación media y superior la preocupación principal son los profesores y a ellos se dirige el concilio en vehemente exhortación: "satisfaciendo colmadamente los deseos de los padres y refutando los oprobios de los anticatólicos, 
merecerán muchísimo de nuestras ciudades y de nuestra Iglesia" $(691,694)$.

Del ámbito de la educación pasan al de las publicaciones. Comprueba el concilio la avidez que se ha desatado en la opinión pública de informarse y leer. Esta avalancha de papel impreso desborda a los obispos y los marea. Impotentes para contenerla, se dirigen a los escritores católicos. Los obispos quisieran quitar de sus plumas los asuntos de filosofia, de moral, de religión; pero reconocen que dado el torbellino actual es útil que escriban, "siempre que lo hagan con licencia de la autoridad eclesiástica y observando los decretos sobre prohibición y censura de libros y con plena dependencia de ella" (729). Ante todo, pues, deben atender al magisterio, que "por Cristo Señor fue encomendado y reservado a la Iglesia" (728), que en el texto se identifica obviamente con la jerarquía. Largamente se explanan las nomas de lo que tienen que decir y cómo deben decirlo (732-741). Se destacan las que se refieren al problema de fe y razón (734-735) y al de religión y pollicica (736-739). En resumen, se les pide que "se rijan por las normas de las enciclicas Mirari vos, Cun Mulio e Inmortale Dei (741) y en concreto, que "luchen valerosa, ordenadamente y de un modo coordinado en favor de la Iglesia" (740).

El problema en este ámbito -expresión del problema de todo el proyecto- es como compaginar el fomento con el control. Se pide a los laicos que sin buscar el lucro y a costa de su tranquilidad se apliquen a la tarea, pero por otra parte se les exige el sometimiento absoluto a las observaciones y la censura de la autoridad eclesiástica.

Para fomentar y a la vez controlar la lectura insisten en la creación de bibliotecas parroquiales públicas (720-721).

Entre las publicaciones a fomentar destaca sobre todo la prensa católica (723727). Hay que fundar periódicos, por lo menos uno en cada diócesis (726).

El tercer ámbito de institucionalización paralela es el laboral. Aqur el enemigo es el socialismo. Establecida la ecuación entre sindicatos y socialismo, para contrarrestar a ambos se insiste en la multiplicación de los círculos católicos de obreros. Y para su eficacia piden que se establezca en ellos "la unidad de la dirección central" (769).

\subsubsection{Sujeto}

Esta institucionalización paralela de la sociedad civil la tienen que ejecutar los laicos, pero es la institución eclesiástica la que planifica, dirige y controla hasta sus últimas concreciones. Por eso el concilio se dirige ante todo a fortalecerla. De ahí que todo el éxito del proyecto dependa de la revitalización de los seminarios. En este contex to cobra sentido esta afirmación: "entre tantas gravísimas necesidades con que se ve apretada la Iglesia de Dios en nuestras vastísimas regiones, la que más debe conmover y excitar el celo, no sólo de los pastores sino también de los fieles, es la de proveer con sumo cuidado a la instrucción de los clérigos" (605). La meta que se traza el concilio es que en cada diocesis haya dos seminarios: el menor y el mayor (609). Pormenorizadamente trazan la estructura, disciplina y orientación de los 
seminarios que ha estado vigente hasta medidados los aflos 60 y que renace hoy (623630). Y para formar a la élite jerárquica el concilio insiste en la necesidad de fomentar y sostener el Seminario Plo-Latinoamericano (797).

Reapuntalada la fomación de los clérigos, se regula minuciosamente lo que concierne a las personas eclesiásticas (título 3), el culto divino (útulo 4), los sacramentos y sacramentales (Lítulos 5 y 6), los beneficios eclesiásticos (Ĺtulo 12), los juicios eclesiásticos (título 15) y todo lo tocante a la vida y honestidad de los clerigos (título 8). Hay buena teología espiritual - de acuerdo claro está con la épocaen los capitulos sobre la vida honesta y la piedad (642-658 y 658-662) y se regulan los ejercicios espirituales (663-666) y las conferencias teológico-litúrgicas (667-672) para su reavivamiento espiritual y su formación permanente.

Restaurada la unidad y disciplina de la institución eclesística,es necesario extender también esta contextura, tanto en el pueblo fiel como en los colaboradores. Nos hemos referido a las instituciones en que debían encuadrarse los fieles.

El fomento del espíitu de este proyecto a la vez que la extensión de la presencia del sacerdote en medio del pueblo se llevan a cabo mediante las pias asociaciones. Se recomiendan por sus nombres las siguientes: "Santísimo Sacramento, doctrina Cristiana, Santísimo Corazón de Jesús, Inmaculada Concepción, Siete Dolores de la B.M. Virgen, las almas del Purgatorio (...) Apostolado de la Oración, Conferencias de S. Vicente de Paúl, Pía Obra de la Propagación de la Fe, Santa Infancia y Escuelas Orientales" (787). Entre las terceras órdenes se destaca sobre todo la de San Francisco (788-789). Estas asociaciones son las mismas que con la Legión de María aún conforman un poco el panorama de lo que aún se mueve alrededor de las parroquias tradicionales.

Por lo que respecta a los contenidos cristianos que deben verterse, el concilio se refiere a la predicación y al catecismo. Sobre la primera dice en resumen lo siguiente: "Advertimos a los predicadores que ajusten completamente sus sermones al modelo del Decreto de SS. Lén XIII a la Sagrada Congregación de Obispos y Regulares de Italia, dado el 31 de julio de 1894 (...) Allí encontrarán la materia que deben tomar para la predicación" (704). La única concreción que explicita el concilio es que no puede faltar la predicación sobre "la existencia, eternidad y rigor de las penas del infierno" (705).

Sobre la catequesis insiste en la uniformidad: "mandamos que dentro del quinquenio en cada república o al menos en cada provincia eclesiástica de América Latina, con el común acuerdo de los obispos, se haga un texto único de catecismo, excluidos los demás, que contenga además un breve sumario de las cosas más necesarias para uso de niffos y rudos" (708). Como fuentes preferentes para su confección se señalan el de San Pio V y el de Belarmino (709). Y no contentos con eso, señalan expresamente las cosas en que debe insistir el catequista (710).

\subsubsection{Conclusión}

El proyecto, como vemos, es expresamente reslauracionista. Su referencia real e 
ideal es la cristiandad; y su enemigo, el mundo moderno que la nicga. Frente a una configuración social que se declara emancipada de la autoridad y guía de la institución eclesiástica, el proyecto se propone crear otra configuración social, sometida como antaño a las directrices de la Iglesia. La oposición es, pues, frontal y la lucha fue frecuentemente dramática.

La raíz de esta pretensión sería la identificación de la Iglesia, es decir la insLitución eclesiástica, con el ámbito de la salvación, "fuera de la cual -dice el concilio en su título primero- no se puede obtener la salvación ni la remisión de los pecados"(51). Si la salvación se obtiene por la profesión de la fe y la práctica de los sacramentos, es necesario que ambos estén al alcance de todos y por lo tanto que la institución eclesiástica, su portadora, sea coextensiva de la sociedad. Este es un mandato divino y, por lo tanto, un derecho que debe reconocer y amparar la sociedad civil.

El concepto de salvación que aquí subyace es sobrenatural en contraposición a natural, positivo en contraposición a histórico. Queda desvalorizada la idea de creación como la cualidad que define positivamente al mundo, al hombre y a la sociedad, y en su lugar campea sin contrapeso la idea de redención unida a la idea de la voluntad absoluta, arbitraria - diriamos- de Dios y comespondientemente del hombre. Desvalorizado el trabajo y el quehacer político como lugares teológicos sólo queda en ellos su carácter oneroso y por lo tanto penitencial y la ayuda que a través de ellos puede prestarse a la instilución eclesiástica. La desvalorización teologica de estos ámbitos lleva como respuesta la resignación a ellos y a sus condiciones actuales, incluso a su consagración positiva si redunda en provecho de la misión de la Iglesia.

\subsubsection{Realizaciones}

Contra la percepción de muchos intelectuales que menosprecian la capacidad de la institución eclesiástica latinoamericana, habría que decir que la reacción es fulgurante. Tanto, que puede hablarse fundadamente de una reimplantación de la insutución eclesiástica en América Latina. Se instituyen, en efecto, los seminarios y uras ellos se erigen nuevas diócesis y parroquias; en cada parroquia una escuela parroquial, además de la Cofradía de la Doctrina Cristiana para el catecismo, y las demás para las devociones y el culto; en las ciudades importantes se establecen periódicos católicos y editoriales de prensa confesionales. Los religiosos, por su parte, refuerzan la educación primaria y la extienden a la secundaria. La institucionalización paralela se extiende de lo educacional a lo laboral mediante los ćrculos obreros católicos, a lo asistencial mediante una verdadera red de hospitales, ancianatos, casas de misericordia, comedores económicos; a lo recreativo mediante una gama variadísima de asociaciones que combinan lo deportivo y cultural con la militancia católica, y a lo político, en la mayoría de los países, mediante los partidos confesionales.

Como resultado de este esfuerzo aparece una institución eclesiástica fuerte y prestigiosa, mucha gente encuadrada y un buen grupo de aguerridos seglares que participan en "el apostolado jerárquico de la Iglesia."6 Puediéramos considerar los 
aflos 50 como los de la culminación del proyecto. En ellos parecían colmadas las posibilidades de ocupar sacralmente el espacio público y el liempo libre. Iglesias, colegios, capillas, cruces de calvarios, viacrucis, misiones, procesiones, peregrinaciones, novenarios, cofradías... poblaron el continente, tal vez en una medida ni siquiera igualada durante la colonia. Pudiéramos decir, entonces, que la cristiandad Latinoamericana había quedado restaurada. En 1955 se rcunió en Río de Janeiro la Conferencia General del Episcopado Latinoamericano. La asamblea expresó la organicidad alcanzada por la institución eclesiástica, y la creación del Consejo Episcopal Latinoamericano (CELAM) sería su prueba más evidente. Por eso, podríamos simbólicamente considerar esta fecha como la culminación del proyecto.

\subsubsection{Limites}

Pero si leemos los documentos de la conferencia, ${ }^{7}$ la percepción cambia por completo. Para los obispos el problema fundamental que afligía a nuestras naciones era "la escasez de sacerdotes," y por eso el objetivo de la conferencia era remediar la "necesidad más apremiante de América Latina," mediante "el trabajo ardiente, incansable y organizado en favor de las vocaciones sacerdotales y religiosas." Los obispos volvieron a urgir la preparación esmerada de los candidalos para que pudieran así "disipar las tinieblas de la ignorancia religiosa de los pueblos," desaparecer "los errores que siembran los acatólicos y los enemigos de la Iglesia" y "combatir de manera asequible la propaganda de las teorias materialistas del comunismo exponiendo con claridad y sencillez las soluciones cristianas a los problemas sociales." Para esta labor, como el clero era insuficiente, debían reclutarse "auxiliares del clero." Y ante la creciente importancia de los mass media deben utilizarse "medios especiales de propaganda."

Es decir, que, bajo el manto de una organización poderosa y de incesantes manifestaciones de religiosidad, los obispos detectaron los mismos problemas de fondo que en 1899: no hay clero local, el pucblo sigue ignorante y la feligresía sigue indefensa bajo el fuego de las mismas amenazas. Ante los mismos problemas decretan idénticas soluciones. Los obispos parecen incapaces de emprender un análisis de por qué persisten los mismos problemas y de por qué fallaron las medidas que enlonces se decretaron. Ni siquiera se les ocurrió plantear qué rasgos deberían caracterizar al cura criollo y cómo formarlo. La institución eclesiástica ya no mira como en 1899 al continente, ha perdido el sentido de la globalidad, de la realidad. Sólo asi se comprende que pueda calificar la escasez de vocaciones sacerdotales como "el problema fundamental de nuestras naciones." El proyecto de restauración de la cristiandad habla entrado en su fase descendente. También, bajo este punto de vista, habría que considerar a esta asamblea como la certificación de que el proyecto como tal estaba consumado.

\subsubsection{La insuficiencia de fondo}

Constatamos que la vigencia social del proyecto conllevaba su vaciamiento. Este fenómeno puede ser explicado mediante el análisis genérico institucional. Pero, 
había también razones teológicas que lo propiciaron. La principal era, a nuestro entender, la dicotomización conceptual y valorativa que privaba de significación al mundo y a la historia y que colocaba la rcalización humana en lo sacral, identificado a su vez, con la institución eclesiástica. En la primera fase del proyecto de restauración, la institucionalización paralela significaba crear un ámbito donde pudiera restaurarse la vida humana, donde pudiera vivirse dc otro modo. El paralelismo era imprescindible para facilitar esta preservación de la vida, en un contexto que se calificaba como minado por la corrupción. Pero el proceso no era automático: para que la institucionalización confesional se constituyera en una alternativa real, exigía una ascética rigurosa, constantes prácticas de devoción, control social consentido. En esta fase surgieron militantes y la Iglesia era una bandera discutida.

Pero con la explosión demográfica, las migraciones y el proceso de modernización, cambió el horizonte cultural, se volvieron imposibles los ambientes homogéneos y la institución eclesiástica, en vez de interrogarse con profundidad, decidió concentrarse en lo fundamental: si lo fundamental no lo adquiere el hombre en sus relaciones sociales, ya que el mundo carece de valor, habrá que lograrlo en otra esfera; es decir, en la sacramental. ${ }^{8}$ Para que los sacramentos fueran accesibles al mayor número había que rebajar las exigencias. Pero, una gracia barata dcjaba de interesar. De allí la masificación de la Iglesia, la alianza con los poderes establecidos necesitados de legitimación y la pérdida de una palabra exigente para no espantar a los clientes ni a los aliados. En estas condiciones, la institución eclesiástica no era ya capaz de reproducirse a sí misma y se dedicaba a sobrenadar, guardando la posición adquirida a costa de carecer de proposiciones. En esta situación se encuentra hoy una parte de la institución eclesiástica. Pero, entretanto, del seno del proyecto de restauración de la cristiandad, brotó un nuevo proyecto.

\section{La nueva cristiandad9}

Como el de restauración de la cristiandad, también el de nueva cristiandad es un proyecto inducido desde Europa, aunque como aquél también encontró en América Latina una base social disponible y de ahí su éxito fulgurante. Para comprenderlo hay que remontarse a León XIII ya que en la "cuestión social" el proyecto no pasará básicamente de la Rerum Novarum ${ }^{10}$ y porque fue este pontílice quien relanzó la neoescolástica que proporcionó el marco teórico de estos hombres. Un segundo hito sería Luigi Sturzo y su Partido del Pueblo. Así describe Caldera su itinerario que resulta ejemplar: "porque ha tenido una fe robusta y un espíritu de inagotable apostolado, el hecho religioso empujo al sacerdote Sturzo hacia la dilatada proyección de lo social; y porque afront 6 lo social con el deseo de llevar hasta los hombres justicia, bienestar y amor, el sociólogo teórico y práctico Sturzo insensiblemente derivó hacia el campo político."ll Un tercer hito sería Maritain; para recordar una fecha podemos referimos a sus lecciones de 1934 que recogería en libro bajo el título de El humanismo integral. ${ }^{12}$ Ahí esta la proposición de la nueva cristiandad y la posición tercerista que caracterizará a este proyecto. De un modo general hay que referirse al catolicismo francés. Dos universidades significativas para este proyecto 
fueron las de Lovaina, especialmente por su escuela de sociologia religiosa (Houtart), y la Gregoriana; también tendrá amplio influjo el Centro Lebret. Como puentes desde América Latina hacia estos centros de Europa y como entusiastas propulsores del proyecto hay que referirse a los jesuitas, a sus revistas y a sus Centros de Investigación y Acción Social (CIAS). Y para tomar un hecho significativo que pueda simbolizar el nacimiento de este proyecto mencionaremos una reunión internacional de Acción Católica en Roma (1933). Allí asistieron dos jóvenes militantes cristianos que pueden quedar como símbolos del éxito de este proyecto pastoral: Eduardo Frei y Rafael Caldera.

\subsection{Sujeto}

El proyecto de nueva cristiandad nació de las ciudades, de la Acción Católica, de los colegios católicos. Nací, pues, del mismo corazón del proyecto anterior. El Concilio Plenario Latinoamericano habla pedido crear asociaciones piadosas y académicas para que los jóvenes, "acabados los estudios, defiendan la causa de la Iglesia y de la justicia." 13 "Es necesario -proseguia - que hombres doctos de diversas ciencias se reúnan en asociaciones libres para que mediante escritos, libros, revistas y simposia promuevan el progreso de las ciencias (...) y se esfuercen en preparar mejores tiempos para la Iglesia y la sociedad,"14

Es lo que llevaron a cabo estos hombres. Ast lo rememora Caldera en 1965: "hace apenas treinta aflos, muchos de los actuales líderes de partidos demócrata-cristianos éramos apenas jóvenes universitarios, empeflados en el estudio de las encíclicas sociales y en los programas de la Acción Católica. Pronto comprendimos que la acción social reclama como uno de sus aspectos primordiales la actividad política; que es necesario deslindar el campo religioso del político; que la política exige la presencia de hombres capaces de trabajar por ideales..."15

Este paso de la Acción Católica a la política implicaba ciertamente deslindar lo religioso de lo político, pero no significaba de ningún modo el abandono de lo cristiano, sino por el contrario su realización cabal. Dice en este sentido Caldera: "por falta de confianza en el Seftor, nos conformamos con los actos de culto, nos cenfimos a arrepentimos y pedir a Dios misericordia, pero nos asustamos con la idea de ejercer el apostolado de la caridad."16 Esto sería, prosigue, "un disfraz de cristanismo muerto, sin el espíritu de Cristo" (id). Así, pues, para este proyecto el lugar central del crisLianismo no era el culto, sino que la fe, la esperanza y la caridad que constituyen el núcleo cristiano se realizaban ante lodo en la práctica social: "el hecho de llamamos cristianos entraña para nosotros una grave responsabilidad: nos obliga a esforzamos por traducir, dentro del campo políico y social, la inspiración, el estado de espíritu que supone la idea de cristiandad." 17 Esta idea de cristiandad es ante todo la de la dignidad de la persona humana: "si por primera vez la idea de la persona humana toma carácter definido con la aparición del cristianismo sobre la tierra, hoy se proyectan en el plano de la conciencia todas sus consecuencias."18 


\subsection{Proposiciones}

Asi, pues, el sujeto de este proyecto pastoral era el seglar comprometido, el "laico adulto" destinatario del célebre libro del teólogo uruguayo J.L. Segundo. ${ }^{19} \mathrm{El}$ objetivo del proyecto era realizar la idea de cristiandad. La novedad de esta cristiandad estribaba en que lo cristiano no se plasmara primordialmente en lo sacral, sino que impregnara al mundo de los valores evangélicos. Estos eran, en sustancia, la dignidad de la persona humana y su dimensión social, de donde se derivó el fomento de las sociedades intermedias, lugar de realización de la sociedad humana, y el principio de subsidiariedad como primera regla de un Estado concebido al servicio del bien común y, por lo tanto, al margen y por encima de cada uno de los grupos y clases sociales.

Estos valores cristianos plasmados de un modo genuino e insuperable en el evangelio, eran los únicos que podían garantizar -a causa de su eminente sentido humano- el encuentro de todos los hombres. Serían por tanto la médula del universalismo y de la catolicidad. Ellos medían también a la institución eclesiástica El laico católico, sujeto de este proyecto, sintió su misión de consagrar el mundo como algo originario, que brotaba directamente de su bautismo. No se trataba de "la participación de los seglares en el apostolado jerárquico de la Iglesia." Según la célebre distinción de planos de Maritain ${ }^{20}$ esta misión la llevaba a cabo el seglar como cristiano, pero no en cuanto cristiano. No comprometía por tanto a la institución eclesiástica y así conservaba también libertad frente a ella.

En América Latina el proyecto eclosiono en los aflos 60, la década desarrollista, y estaba estrechamente emparentado con la Alianza (contra Cuba) para el Progreso. En 1966 fue oficialmente asumido por la institución eclesiástica al más alto nivel ya que se reunieron expresamente para ello en Mar del Plata en una asamblea general extraordinaria. El documento, titulado "Presencia activa de la Iglesia en el desarrollo y en la integración de América Latina," anima a reorientar las instituciones y a reciclar a los agentes pastorales para participar en el desarrollo integral del continente. Se alientan especialmente la educación para el desarrollo y las instituciones de promoción, sobre todo las cooperativas.

El documento asienta que es incumbencia de la Iglesia orientar el desarrollo "hacia una promoción de las personas humanas en todas sus dimensiones y hacia una integración completa de las poblaciones marginales." 21

La promoción, concebida como paso de la marginación a la integración, se inscribía en las coordenadas civilización-barbarie. Las masas rurales y suburbanas estaban marginadas ante todo de las luces y los beneficios de la civilización; ahí estarla la explicación de su estancamiento: viven como en la colonia, no han tenido acceso al mundo modemo. El mundo moderno no es nuestro mundo, sino lo que del occidente desarrollado ha logrado introducirse en él. Nuestro continente seria materia virgen para que lo moldcara el occidente desarrollado. Nuestra principal virtud, la capacidad de aprender, el instinto de imitación, la ductibilidad. Esto, también en la esfera religiosa. La cristiandad latinoamericana, para estos cristianos promovidos y modernizados, no pasaba de tradicionalismo rutinario, devoción sin insınucción, supers- 
tición y magia sin evangelio. No merecía la pena restaurar tal cristiandad. Se trataba de promover una nueva cristiandad

Esta nueva cristiandad serfa la cristiandad del norte de Europa, reconciliada por fin con la ilustración y el mundo moderno, la que pasó del anatema al diálogo, de la pretensión de una institucionalización paralela a la participación en el orden establecido como una de sus fuerzas configuradoras, con su correspondiente cuota de poder. Naturalmente que dentro del sistema y como evolución de él se aspiraba a la justicia social, a la sociedad participativa, incluso a la cogestion y al comunitarismo; pero dentro del sistema. Los ideales no medfan al sistema y lo forzaban a transformarse, sino que eran medidos por él y acabaron convertidos de motivaciones eficaces en declaraciones de principios. Esta era la nueva cristiandad propuesta para Latinoamérica. Ponerse cristianamente al dla significaba ponerse al día de Europa. Se trataba, en definitiva, como lo teorizara Alberdi22 de proseguir la colonización. ¿Por qué estancamos y considerar como criollo lo del período ibérico y como extranjero lo importado después? También en el plano religioso la colonización española fue insuficiente; es necesario completarla abriendo las puertas a los centros mundiales de producción cristiana. Eso serfa la nueva cristiandad.

\subsection{Realización latinoamericana}

Y como en el área económica se importaron técnicos y capitales, asl en el ámbito cristiano durante tres décadas vertiginosas llovieron recursos, agentes pastorales, libros e infinidad de cursillos. Se implantó el culto en lengua vemácula, las cofradias cedieron espacio a asociaciones y movimientos, los crucifijos se retiraron ante Jesús resucitado, fueron arrinconados los santos, las iglesias oscuras y las numerosas imágenes doloristas (donde se pudo) fueron sustituidas por construcciones funcionales y por alguna otra imagen abocetada y vitalista. Ya los cures no predicaron del infiemo ${ }^{23}$ ni clamaron contra el sexo, desaparecieron los cantos ancestrales y tremendos. Ya el mundo no era "este valle de lágrimas," ni el lugar de la tentación ni del pecado. El mundo era bueno como creado por Dios. $Y$ no estaba ahí para la contemplación sagrada: Dios lo había entregado al hombre para que lo fecundara con su trabajo. Por eso la vida familiar y social y el trabajo eran los lugares y ocupaciones en donde el hombre debía santificarse. En el proyecto de restauración de la cristiandad, al estar desprovista la naturaleza de valor sagrado, la santificación habla que buscarla en lo que iba más allá de la naturaleza: mortificaciones, devociones, renuncias que culminaban en los votos de pobreza, castidad y obediencia. En esta nueva cristiandad se trataba por el contrario de ser plenamente humano, no otra cosa era el cristianismo, ya que Jesús es el Hombre Nuevo. De ahl que Pablo VI definiera a la Iglesia como "experta en humanidad." 24 Teilhard de Chardin, el jesuita paleontólogo y místico, fue el ejemplo más acabado así como el iluminado inspirador de este cristianismo, amador apasionado del mundo, que se trasciende en el trabajo por perfeccionarlo a la vez que lo contempla como "medio divino."

Asf como en Europa este proyecto se aplicó sobre toda la reconstrucción material y espiritual del continente devastado por la guerra, en América Latina encontró 
campo abierto en las tareas del desarrollo. Y hay que reconocer que la Iglesia latinoamericana dio un verdadero vuelco para ponerse a su servicio. En este sentido, el documento de Mar del Plata, más que proyecto, se reduce a expresar y consagrar lo que a gran escala llevaban a cabo muchos cristianos latinoamericanos. De ahi que, junto con la culminación, marcó también simbólicamente el límite al que habfa llegado el proyecto. Ya estaban a la vista las limitaciones y contradicciones de este esquema que fue incapaz de llenar las expectativas que provoco: no sólo no se avanzaba en la integración de los marginados, sino que algunas voces proféticas, como la de Helder Cámara ante esta asamblea de obispos, 25 empezaron a seflalar que no sólo no era posible, sino que ni siquiera era deseable integrar a nadie en esta sociedad injusta, que más bien habla que desolidarizarse de ella y transformarla desde sus cimientos.

Pero en esta oportunidad se trataba de voces que clamaban en el desierto. Estos clamores no eran audibles porque los sujetos de este proyecto se encontraban en plena expansión de personas, obras y energfas. Se trataba de los grupos sociales que a través de la educación habían emergido como élites modemizantes y que, precisamente, en esos affos estaban definiendo con los hechos su peso y su signo histórico.

\subsection{Límites e insuficiencias}

¿Cómo es posible entonces que sólo 2 años después la Segunda Conferencia General del Episcopado Latinoamericano reunida en Medellín suscribiera enfáticamente el juicio de Helder Cámara?26 La respuesta tiene que ver con la radicalidad y seriedad con que muchos cristianos se empeflaron en este proyecto, ya que fue precisamente su realización la que puso al descubierto la debilidad de algunos de sus presupuestos.

Una de las principales estribo en que mundo y hombre se concibieran como naturaleza, no como historia Se percibió un mundo en expansión y al hombre como punto de lanza de la evolución. De ahl los conceptos de desarrollo y de promoción. El presupuesto era que naturaleza, hombre y sociedad constituian un todo continuo, homogéneo y orgánico. En este esquema las clases sociales expresaban funciones naturales y complementaries del todo. Claro que se veían los males sociales, pero se conceptualizaban como abusos. De ahi el lema de Caldera: "para que las instituciones sobrevivan, es necesario que cambiemos las estructuras."27 Estas instituciones serfan la familia, el municipio, el sindicato, la propiedad, la nación, el Estado, la Iglesia...

En este contexto cambiar las estructuras significaba acondicionarlas de tal manera que garantizaran el equilibrio de la institucionalización actual, elevada a la categoría de natural y, por lo tanto, sagrada. El equilibrio de la empresa, por ejemplo no significaba la socialización de los medios de producción, sino el salario justo; en la familia no implicaba la redistribución de funciones para acabar con el predominio masculino, sino cumplir lealmente con las reglas de juego establecidas, y así en las demás instituciones. De este modo, la institucionalización actual, como fruto de la naturaleza perfeccionada por el cristianismo, quedaba elevada a la categorfa de paradigma. Los cambios eran en orden a realizarlo y perpetuarlo. Esta ideologia fue 
funcional para una clase social ascendente que demandaba sitio e idealidad para su tarea y juego limpio en el proceso.

\section{Los procesos: la ruptura instauradora}

¿Cómo se pasó de esta concepción organicista a una visión histórica? Podriamos señalar el influjo de figuras como Mounier, 28 libros como Desarrollo sin capitalismo de Silva Solar y Chonchol, 29 documentos como la enciclica de Pablo VI Populorum Progressio, ${ }^{30}$ símbolos como Camilo Torres. ${ }^{31}$ Pero nos parece más significativo tipificar los procesos concretos de estos cristianos latinoamericanos, sobre todo porque, con las variantes del caso, siguen funcionando como caminos que transita un número cada vez mayor de cristianos e incluso de instituciones.

\subsection{De la promoción popular al compromiso con el pueblo oprimi- do}

Una parte muy significativa de la institución eclesiástica se metió en el seno del pueblo para contribuir a su desarrollo. La plataforma más usada fue la educativa, ${ }^{32}$ pero entendida de un modo bastante integral ya que abarcaba a nifos y adultos y tenía en cuenta los aspectos informales tanto como los formales, la educación para el trabajo y en la vida. En las aulas además se reunian los vecinos para cuestiones reivindicativas, organizativas, culturales y por supuesto religiosas.

Se lograron algunas rápidas mejoras y se despertaron muchas expectativas. La gente se puso en marcha con creatividad y coraje. Pero la promoción llegó a un techo. En estas condiciones ocurría que el impulso inicial se adaptara a las condiciones establecidas. O también ocurria que el anor eficaz que impulsó el proyecto no se resignara a realizarse dentro de lo posible en el sistema. A través de anecdotas frecuentemente dolorosas y desconcertantes para sus protagonistas, se alcanzaba a percibir que la estructuración social no era algo natural, sino que su fin era reproducir las relaciones sociales vigentes. Al captar su carácter histórico (una clase social la creó para fomentar y reproducir sus intereses) dejaba de ser sagrada; era juzgada y condenada como "violencia institucionalizada" 33 Se opero una inversión: el amor eficaz comenzo a funcionar como absoluto y la estructuración social como relativa; no era ya el amor el que debla redimensionarse según la situación, era la situación la que debía ser transformada de modo que expresara el amor.

El amor al pueblo al que se quería promocionar se convirtió en lazos concretos con gentes con nombre y apellido. De este modo, el que vino como representante de una institución a extender la institucionalización vigente a donde terminaba el asfalto ${ }^{34}$ se transformó insensiblemente en alguien que iba echando raices en el pueblo y que ahora trataba de representar al pueblo ante aquellos que lo enviaron. Este deslizamiento de solidaridades en muchos casos llegó a ser definilivo. Entonces vino el repudio por parte de su clase de origen. Se experimentó en carne propia la brecha de las clases sociales. Ahora se sabía que la sociedad no era un continuo. El esquema marginación-integración no era válido ni como explicación de la situación ni como método de trabajo. Los pobres no eran los que todavla eran pobres (primitivos, tra- 
dicionales, subdesarrollados), sino los empobrecidos (secular y modernamente). Eran las clases oprimidas, las culturas dominadas, las razas discriminadas.

El que el amor que es universal tuviera que expresarse desde una parcialidad (el pueblo) y a través del conflicto, no fue fácil de digerir para unos hombres formados en la prédica de la amnonía, el diálogo y los grandes conceptos universales. Pero al pasar de la promoción al compromiso aparecieron nuevos lazos sociales y éstos compensaban con creces.

\subsection{Del testimonio evangélico a la participación en las relvindica- ciones y la organización popular}

El proyecto de restauración de la cristiandad insitfa en que las acusaciones a la Iglesia, fuera de algunos abusos achacables a la debilidad humana, no tenían más base que la malevolencia de sus enemigos. Pero al proponerse una nueva cristiandad cundió el convencimiento de que, al menos por inconsciencia y desadaptación, se había dado pie a las críticas. Entre los afios 50 y 60 un número significativo de cristianos, sobre todo religiosos (as), se lanzaron a "dar testimonio" (como entonces se decía) de que el cristianismo era algo radical; y se fueron a vivir entre los pobres. Desechaban cualquier tipo de liderazgo, impresionados por la vieja acusación de clericalismo, y sólo pretendieron vivir como los demás. La gente agradeció la cercanía, pero no entendió la negativa a desempefiar funciones.

Estos cristianos, pasada la fase dificil del reacomodo, se encontraron con un malestar secreto, como desempleados. Y los mejores de ellos, a través de ocasiones ineludibles, se fueron ligando a la gente, a sus problemas, a sus luchas. Entonces desapareció el primitivo encanto; las personas que desde fuera los habían visitado y admirado los miraron ahora con sospecha y hostilidad. Ellos dieron un salto antropológico: no se trataba de vivir como los demás, sino de relacionarse orgánicamente con ellos. Descubrieron que el hombre no se define por la intuición sensible, sino por la red de relaciones que entabla y que lo constituye. En este punto desapareció la universalidad de los atributos humanos abstractos y quedó el conflicto entre redes de relaciones. Entonces entendieron que el testimonio de que la Iglesia estaba con los pobres no implicaba sólo una cercaní física y afectiva, sino que únicamente se realizaba al ligarse con ellos en relaciones sociales transformadoras. Unicamente, ya que cualquier otro empobrecimiento siempre quedaba por encima del medio en que estaban insertos porque aun en las bases más pauperistas siempre subsistra la posibilidad de desandar el camino y la seguridad institucional: ellos hablan elegido el medio, podlan entrar y salir de él, conservaban de hecho otras relaciones; mientras que los pobladores estaban en el barrio como una condena. Por ese camino nunca llegarian a encarnarse. La única vía posible era el compromiso: ser de ellos. Pero eso implicaba el paso de una institución eclesiástica comprometida con el status a la Iglesia de los pobres.

\subsection{De la renovación pastoral a la evangelización liberadora}

El concilio Vaticano II propulsó la renovación pastoral en los métodos, el estilo 
y hasta los mismos contenidos. No se trataba de hacer prosélitos ni de un estilo dogmático y disciplinario. Se trataba, tanto al interior de la Iglesia como con todos los hombres, de estimular el diálogo, la participación y la comunión.

Por lo que respecta a los propios cristianos, dos reformas muy notorias fueron la litírgica y la bfblica, que no pocas veces marcharon conjuntamente. En América Latina sobre todo a nivel popular, se empezó a leer la Biblia en grupos, y el sacerdote o la religiosa instaba a que cada quien expresara cómo la entendía y qué le reclamaba. Casi sin darse cuenta el pueblo fue tomando la palabra, la palabra propia y la palabra de Dios. La palabra de Dios fue dando a luz pública unas palabras de ellos que eran realmente nuevas y que los llenaban de asombro. Veían claramente que Dios es el Dios de la Vida, que él quiere para el pueblo vida solidaria y abundante. Por lo tanto, la vida que estaban viviendo no era voluntad de Dios, era resultado de la opresión de otros hombres. Dios rechazaba a los opresores; el impulso a unirse, a ayudarse mutuamente, a capacitarse, a liberarse procede de Dios. Estos descubrimientos en común alentaron acciones en común.

Llegados a este punto hubo agentes pastorales que creyeron que las aguas se habian desbordado, y lo cortaron en seco o lo reglamentaron de modo que se restableciera el orden tradicional. Pero otros comprendieron que eso es la Iglesia: llevarse mutuamente en la fe, en el evangelio y en el compromiso liberador. ${ }^{35}$ En Brasil, en Los Andes, en Centroamérica y un poco por todas partes esta práctica dio origen simultáneamente a procesos sostenidos de liberación y a una verdadera "eclesiogénesis, "36 es decir, a un proceso de creación de Iglesia, la Iglesia que nace del pueblo. ${ }^{37}$

\subsection{De la acción política desde la "tercera vía" al socialismo de rostro humano ${ }^{38}$}

El esquema tercerista pretendía la superación dialéctica del capitalismo liberal y del colectivismo marxista De este último asumía la justicia social y negaba la supeditación de la persona al Estado y al partido. De aquél retenfa la libertad y rechazaba el individualismo y el materialismo de la ganancia como motor universal. Con esta operación pensaba obtener la justicia social en libertad, que serfa la caracteristica del proyecto.

Ahora bien, desde la mera ideologia ıcómo distinguir una dialéclica nominalista de una real? ¿Cómo saber si se proponía o no un nuevo sistema? La respuesta la dio la práctica en la segunda mitad de los años 60 . Aun valorando de un modo positivo las experiencias de Frei y Caldera, parece bastante difícil sostener que ellas significaran lo que en 1965 calificara Caldera como "una posición revolucionaria "39 La tercera vif propuesta no entrafiaba un nuevo modo de producción, sino que ostensiblemente se inscribla en el modo de producción capitalista; pero sí significaba la irrupción de las clases medias demandando a la burguesía una cuota de poder e incluso la hegemonfa. Ante esta realidad no pocos cristianos comprendieron que el ideal de justicia social en libertad no implicaba un sistema social propio y que en el sistema capitalista era irrealizable. Entonces surgió la pretensión del volcar ese potencial políti$c o$, afincado en las clases medias, en una alianza con las clases populares para un proyecto socialista democrático. 


\section{Teología de la liberación ${ }^{40}$}

Hemos esbozado los caminos más habituales por los que cristianos o grupos de cristianos transitaron del proyecto de nueva cristiandad al de liberación integral. Vamos a caracterizar este último sumariamente. ${ }^{41}$

\subsection{Un proyecto latinoamericano}

Ante todo hay que decir que no es un proyecto pastoral inducido desde el exterior como los anteriores. Es un proyecto genuinamente latinoamericano. Porque, como en el siglo XVI, América Latina volvió a ser un lugar teológico, ${ }^{42}$ es decir, el contexto primario en el que se manifiesta la voluntad de Dios. Para saber qué quiere Dios de nosotros, qué hemos de hacer, no miramos ante todo a las directrices de Roma o a las elucubraciones de los teólogos europeos. No es que las despreciemos, sino que las consideramos como mediaciones, imprescindibles sin duda, pero mediaciones. Porque para saber lo que quiere Dios de nosotros ahora miramos ante todo a lo que el Concilio Vaticano II llamó "los signos de los tiempos." 43 Porque nuestra fe se ha decantado como amor eficaz, se ha convertido en fe que busca entender para hacer la verdad. Cristianos así son capaces de escuchar aquella frase de Jesús: " $¿$ Por qué no juzgan ustedes mismos lo que hay que hacer?" (Lc. 12,57).

\subsection{Una nueva interpretación}

Esta nueva visión compondría un verdadero círculo hermenéutico formado por tres niveles que mutuamente se interprelan. El primer nivel, el más originario y fundante, sería el del corazón de carne que se duele de las necesidades y de la opresión del pueblo. No hay nada anterior a este nivel ya que la certidumbre cientílica y las mismas certidumbres teológicas vienen a su zaga ya que "no están hechas para suplir la rectitud del corazón humano como fuente primera de todo juicio histórico."44 Este corazón humano sería el corazón del Dios biblico que no puede soportar impávido el clamor de los oprimidos (Ex. 3,7-8); sería el corazón de Jesús de Nazaret que sentía compasión por la gente (Mt. 14, 14) y que se solidarizó completamente con el pueblo del que formaba parte.

A través de esos procesos que tipificamos anteriomente, este corazón que Dios renueva (Ez. 36,26; Sal. 51,12) realiza la experiencia espiritual que está a la base de la teología de la liberación. ${ }^{45}$ Se expresa en tres canales primordiales: la contemplación, la praxis de liberación y la ternura, dimensiones absolutas, imprescindibles y mutuamente conectadas. La contemplación se realiza en la praxis de liberación cuando en los rostros concretos reconocemos el rostro del Señor; ${ }^{46}$ entonces es capaz de custodiar y plenificar a la praxis y al carifio. La ternura, el amor concreto, el cara a cara insustituible impide que la praxis de liberación, por su propia dureza, se traicione a sí misma, y que la contemplación degenere en proyección narcisista o huida idealista. Y la praxis de liberación empuja a la contemplación y a la temura a trascender y a verificarse.

Ese corazón abierto al dolor del pueblo es el que lleva a elegir un determinado instrumental cientifico ${ }^{47}$ (y este seria el segundo nivel) que critica la modemización 
propuesıa por las élites y califica de colonialismo intemo su pretensión de liderazgo, y de violencia institucionalizada el orden creado por ellos, y llega hasta la denuncia del desarrollo dependiente propuesto por las transnacionales como imperialismo, como acto de injusticia y de violencia que impide la paz.

Como tercer nivel vendría la lectura teológica de la situación que la califica de situación de pecado porque al imposibilitar la paz social y la paz interior implica un rechazo de Dios mismo: cuando la fratemidad es negada se está negando a Dios Padre.

\subsection{El pueblo organizado, nuevo sujeto}

La proposición fundamental de este proyecto histórico consiste en convocar al pueblo a asumir su destino: "alentar y favorecer todos los esfuerzos del pueblo por crear y desarrollar sus propias organizaciones de base" (Medellín, 2,27).

Frente a la llamada del status a encuadrarse y consumir, frente a la masificación de los populismos y la burocratización de la mayor parte de los socialismos "reales" en el poder, el santo y seña, la piedra de toque de este proyecto es la participación popular.

Desde la fe en el Espíritu de Jesús que sopla hoy en nuestra historia decimos sólo el pueblo salva al pueblo. Esto no lo decimos como slogan entusiasmador y vacío. $\mathrm{Ni}$ lo decimos como expresión mítica incomprobable. Lo decimos como proyecto histórico. Es decir, todavía no es verdad que sólo el pueblo salva al pueblo. Lo que sí hemos comprobado - y ya es mucho - a lo largo de nuestra historia es esta verdad: el no-pueblo no salva al pueblo. Y esta otra, el pueblo salva al no-pueblo. En nuestra historia nunca se ha salvado al pueblo desde arriba, y es el pueblo el que, convocado por otras clases, las salvó a su costa. Por eso, ahora decimos, apostamos, pretendemos: sólo el pueblo salva al pueblo. Y también creemos que salvará a los que no lo son, por afladidura. Por eso, frente a las eternas promesas incumplidas, proponemos como altemativa la organización popular.48 Es una proposición histórica, abierta, por tanto, a la incertidumbre del futuro. Decimos que con nosotros lucha Dios. No pretendemos que el éxito de nuestros planes, quede garantizado. No decimos, el pueblo unido jamás será vencido. Esperamos, no más, que algún día no lo sea y que sepamos, entonces, custodiar nuesira victoria.

Esta proposición fundamental tiene que ver, desde luego, con los partidos socialistas y con los sindicatos clasistas. Este proyecto conoce otras muchas formas de organización popular. Pero sabe que no puede realizarse en contra de los partidos socialistas y de los sindicatos clasistas. $Y$ aquí hay una fuente de conflicto, dado el estado actual en muchos de nuestros palses de este tipo de organizaciones, y dado también que los grupos cristianos se han integrado en ellos tardíamente. Es un proceso complejo. Pero de un modo general sí se puede decir que la atomización y el sectarismo sólo se superan cuando estas organizaciones se dirigen decididamente a la organización popular y saben dar a la base participación y responsabilidad.

Sin embargo, no son éstos los únicos ni los principales canales. Más aún, sólo lograrán liberarse de sus contradicciones históricas si son custodiados por muchos 
otros grupos populares que alcancen a constituir en el seno del pueblo una verdadera tela de araña institucional. Esta es la dirección primordial que con singularidad y creatividad está recorriendo en América Latina este proyecto pastoral.

\subsection{Una Iglesia renovada desde la base}

De esta lucha por organizar al pueblo cuando se la realiza desde el Espíritu de Jesús y está presente la contemplación y la temura, nace la Iglesia popular49 y como su corazón las comunidades de base. .50

En este proyecto de liberación integral el sujeto evangelizador es el pueblo evangelizado, es decir, el pueblo - que es cristiano- que resiste, lucha, ora y espera. Es también sujeto imprescindible - secundario en el proyecto, principal en sus fases iniciales- la institución eclesiástica: religiosas, curas y obispos comprometidos con el pueblo, solidarizados como intelectuales orgánicos con las clases oprimidas.

El destinatario inmediato, pero real, de este proyecto es todo el mundo. El destinatario directo es el pueblo oprimido a quien se le anuncia que Dios está comprometido con su liberación. En segundo lugar, las otras clases sociales a quienes como ganancia para ellas se convoca a que se la jueguen por la liberación del pucblo poniéndose a su servicio. En tercer lugar se dirige como mala nueva a los opresores recalcitrantes: Dios es parcial, está contra ellos.

Tenernos que decir con alegría que a través de estos años se ha consolidado en nuestro continente esta Iglesia popular. Diariamente se reúne en cicn lugares. Se dispersa por toda nuestra geografía. Se interna por nuestros barrios. Se hace presente en el trabajo y en la universidad. Son personas nacidas en el pueblo o que, proveniendo de otras clases, han cambiado sus solidaridades y están en proceso de una opción estable y madura por la clase oprimida. Son grupos jovvenes - aunque hay personas con muchos aftos en la pelea- y se sienten débiles, y lo son, pero con su debilidad son capaces de fortalecer a quienes viven a su alrededor.

Su palabra de orden es poder de base. Por eso en sus acciones insisten en estructuras democráticas y participativas y en sus métodos de acción tratan de lograr consenso.

Consecuentes con su objetivo de articulación popular todos estos grupos insisten de uno y otro modo en la educación liberadora, en la concientización.

Son grupos capaces de cargar con un alto costo social; esfuerzos constantes de adaptación, de autocrítica, de creatividad, tenacidad en los esfuerzos, capacidad de resistir la lentitud del proceso, y los fracasos y la austeridad. Y sin embargo, la angustia económica no obsesiona ni encierra en el egoísmo; se es capaz de compartir, de dar y recibir compañia, y -a pesar de la fatiga del trabajo- hay gran sensibilidad por lo lúdico y no escasean los ratos de auténtico gozo.

Para esta Iglesia popular Jesús de Nazaret es indisculiblemente la fuente de inspiración. Jesús es sentido, ante todo, como el hombre fiel: fiel a su misión de proclamar la posibilidad y la inminencia de un mundo como Dios manda, fiel a su camino de compromiso con el pueblo y denuncia de todo tipo de opresión, fiel a su 
estilo de permanecer en la base como quien sirve, fiel cuando crecía la oposición, fiel en la represión, fiel en el suplicio. Y fiel ahora en su presencia entre nosotros. No se siente a Jesús como un ser ante el cual hay que postrarse. Más bien se le siente grande porque continúa hoy sirviendo, dando inspiración y guia. Por ser fuente de vida se le siente único e insustituible, nuestro hermano mayor. Asi sentimos al Hijo de Dios.

Hay que decir que entre los aportes de eslos grupos a nuestra Iglesia, uno y bien apreciable, es el redescubrimento de la misa como un encuentro, como un esfuerzo de comunión en el que acontece la presencia confortante de Jesús. Y allí se confiesa la fe, alli se ora, se pide perdón y ayuda. Allí se sumen de nuevo en la fuente del compromiso libertador. Alli, finalmente, se invoca al Padre de Jesús como a nuestro Dios y se le pide su Espiritu de hijos y que apresure la llegada de su reino.

\subsection{Dí́logo histórico desde la religión del pueblo 51}

Para el pueblo latinoamericano la religión, como sus otras dimensiones humanas, ha sido y es una realidad ambigua: ella le ha ayudado a asumir como sagrada la constitución jerárquica de la sociedad, a considerar a los de arriba como representantes de Dios, a resignarse a su puesto como voluntad divina y a despreciarse a sí mismo como ignorante de las cosas de la religión, recienvenido al cristianismo y exterior a la institución eclesiástica. Esto es indudable y sus raíces se remontan más atrás del cristianismo. Las religiones amerindias en no pocos casos han refrendado además una visión ritual del mundo en la que el sacrificio ocupa el lugar central. Todo esto impide sacralizar románticamente la religión del pueblo. Pero la religión también ha ayudado al pueblo a resistir a todo eso y es potencial de primer orden para superarlo. La religión ha sido el principal vehículo para que el pueblo conserve su identidad, la conciencia de su dignidad, el sentido del respeto y el anhelo irrenunciable de pureza y armonía. La religión ha mantenido al pueblo compacto, diferente, genuino ya que a través de ella ha expresado su condición de sujeto y su creatividad.

Cuando agentes pastorales han podido reconocer la sustantividad de la religión del pueblo y su potencial evangelizador han entrado en ella no mediante un mimetismo encubridor, sino a través de un diálogo histórico: la palabra de Dios que recibían en el seno del pueblo era la que obligaba a sacar a la luz las tradiciones religiosas de los agentes pastorales y del pueblo y a discemirlas. A lo largo del proceso se va operando el reconocimiento de la calidad liberadora de lal práctica o representación y así se va superando lo negativo y transformándose los sujetos y sus expresiones. Transformándose mutuamente, no ya accediendo simplemente las personas populares a la religión de la institución eclesiáslica.

El hallazgo de este camino es que, hablando en grandes números, el pucblo latinoamericano puede ser descrito con el binomio: creyente y oprimido, en el que ambos términos no describen un modo de ser, sino una constitución histórica contradictoria en busca afanosa de resolución. De ahí su potencial liberador. 


\subsection{La lucha ideologica52}

Este proyecto nace en una sociedad que se autolitula cristiana y que pretende legitimarse por su carácter de portadora y defensora de los valores cristianos constitutivos de América Latina y actualmente amenazados. Por eso, este proyecto, si quiere llegar a las mayorías, conlleva una lucha ideológica que desenmascare estas pretensiones del orden establecido.

$Y$ ante todo, la invocación a la paz y a la unanimidad del pueblo cristiano, ya que no se trata de conservar la paz que no existe - lo que existe es la institucionalización de la violencia - sino de edificar la paz cristiana basada en la justicia y en la supresión de las discriminaciones, porque la unidad para los cristianos sólo se logrará cuando todos nos decidamos a transitar el mismo camino liberador que recorriera Jesús. En este camino urge rescatar el sentido cristiano del conflicto, 53 ya que si nadie quiere exacerbarlo gratuitamente, tampoco es digno de un seguidor de Jesús eludirlo por cobardfa; en este mundo en pecado no puede constituir un ideal cristiano el evitar a cualquier precio el conflicto. Como un caso de conflicto estŕ el problema de la violencia. 54 En primer lugar, tenemos que denunciar la violencia que hoy se ejerce en gran escala contra nuestro pueblo por parte de las empresas, de los medios de comunicación y de los gobiemos. En segundo lugar, hay que asentar que los cristianos amamos la paz y detestamos la violencia, y en nuestra utopía está el acabar para siempre con ella. Pero, tenemos que decir también que el cristiano "no es simplemente pacifista, porque es capaz de combatir."55 Sin embargo, cada vez vemos más claro que el acceso del pueblo a la calegoría de sujeto histórico, desde nuestra perspectiva cristiana, marca netamente la prevalencia de la resistencia y la acción desde las comunidades, grupos y organizaciones sobre la violencia armada, militar o paramilitar. Este salto histórico equivaldría a una revelación más profunda del Dios cristiano y de la propia humanidad del hombre. 56

Dos bloqueos que paralizan aún hoy esta lucha por la justicia son la sacralización del derecho de propiedad privada y la acusación lanzada, al parecer sin apelación, contra cualquiera que intente hacer algo, motejándolo de manxista-ateo, de comunista.

Por lo que respecta a la propiedad, el status cada vez se atreve menos a invocarla. Es muy difícil hacerlo cuando la base teológico-cristiana es tan endeble, y son tantos los textos de la Biblia, de los padres de la Iglesia y de los teólogos clásicos que la relativizan y la subordinan al único absoluto: la destinación universal de los bienes de la tierra. 57

La acusación de marxismo ${ }^{58}$ aún resulta eficaz para paralizar muchas acciones de los grupos cristianos. Habría muchas razones. Una, que aún la Iglesia institucional no ha tenido tiempo para situarse matizadamente ante este fenómeno, aunque la carta de Pablo VI, Ocrogésima Adveniens, supone un gran paso en este camino. Otra tendría que ver con los dogmas que persisten en la filosofia marxista de signo atco y militante, aunque una parte de los teóricos actuales y algunos partidos están en camino de superarlos. Pero la razón más importante está en la manipulación interesada de los medios de comunicación social que aterrorizan al pueblo y a la institución eclesiástica con premoniciones catastróficas en las que ellos no creen, pero que sirven 
para inmovilizar los esfuerzos para superar este sistema opresor basado precisamente en la propiedad privada.

Hay muchas otras manifestaciones de esta lucha ideológica, pero el núcleo consiste en derribar como Idolo una imagen de Dios ${ }^{59}$ basada en la absolutización de las jerarquías terrestres con su correspondiente imagen de salvación y de Iglesia.

\section{Coyuntura actual}

\section{La actual correlación de fuerzas}

Descritos los tres proyectos históricos que operan en el cristianismo latinoamericano actual, analicemos la correlación de fuerzas dentro de la institución eclesiástica. Ya seffalamos a la asamblea extraordinaria de CELAM de Mar de Plata (1966) como el momento en el que el proyecto de nueva cristiandad se expresa en plenitud. En la II Conferencia General del Episcopado Latinoamericano (Medellín, 1968) el proyecto de nueva cristiandad se asoció con el de liberación, y como resultado, el de restauración quedo ausente de los documentos finales. No necesitamos insistir que lo que afirmamos expresa el resultado objetivo de un movimiento histórico y no el producto de manejos o conspiraciones. Resulta paradójico que, siendo Medellín la expresión del relevo de la hegemonía del proyecto restaurador por el de nueva cristiandad, sus documentos, en cambio, estén tan frecuente y fuertemente coloreados por el de liberación de manera que constituyen todavia hoy su referencia simbólica. La paradoja se explica si tomamos en cuenta que para 1968 los tópicos del proyecto de desarrollo integral estaban en la mayor parte del continente absolutamente desgastados, en tanto que venía surgiendo un lenguaje emergente y motivador. el de la liberación.

En vísperas de la III Conferencia General del Episcopado Latinoamericano (Puebla 1979) la correlación de fuerzas no era nada clara. Por una parte el proyecto de nueva cristiandad, mayoritario, encontraba muy poco espacio histórico para expresarse: la situación sociopolítica dejaba escaso margen para la promoción popular y la reforma de estructuras para la justicia social. Por otra, los gobiemos conservadores y aun represivos del continente unánimemente se proclamaban protectores de la Iglesia y promotores de la "sociedad occidental y cristiana." Su propuesta era halagadora para el proyecto de restauración de la cristiandad, que sin embargo, no podía menos que resentir la depauperización del pueblo y la sistemática violación de los derechos humanos. Sin embargo, también anotaban, por efecto de la situación desesperada, un aumento de clientela para la probada capacidad asistencial de la Iglesia y un aumento de religiosidad. Para este proyecto los gobernantes, aun con reparos, eran interlocutores válidos. Pero por otra parte, el proyecto de Medellín iba ganando nuevos adeptos. Lo más notable, por su organicidad y su peso, eran la Iglesia brasilera que no sólo a nivel de declaraciones sino a nivel organizativo había avanzado cualitativamente en el compromiso popular, y la vida religiosa que venía recuperando a ritmo acelerado su identidad carismática y su misión profética y que estaba demostrando, sobre todo en la rama femenina, una capacidad de cmpatar con el pueblo que 
pocos hubieran imaginado. Pero por todo el continente floreclan los grupos populares y nuevos obispos se incorporaban a esta pastoral de liberación integral.

En estas condiciones el CELAM, dirigido por el obispo colombiano Alfonso López Trujillo, promovió una nueva correlación de fuerzas. Para cerrar el paso al proyecto de liberación, el de nueva cristiandad se alió con el de restauración. La base de la alianza fue la proposición (muy funcional para el status del continente) de inslaurar una modemización sin secularización. Es decir, modemización y conservación y fomento de la religiosidad popular, entendida como multitudinaria y masiva. Esto implicaba modernización, pero preservación del estatuto estamental de la Iglesia católica. La proposición era inteligente y se lleva a cabo de un modo extremadamente organizado y consecuente: la brecha entre ricos y pobres se cerrará con el desarrollo. El desarrollo requiere compactación social. En América Latina la Iglesia católica es la institución con mayor poder de convocación y unificación. Por lo tanto, si los gobiemos respetan los privilegios de la Iglesia y humanizan la opresión, la Iglesia jugaría su peso por el desarrollo según el esquema vigente. Para que esta estrategia uuviera éxito habia que descalificar previamente el proyecto de liberación. Esta es la estructura que vertebraba el "Documento de consulta a las conferencias episcopales," que el CELAM editó en 1978 como preparación a Puebla.

Esto fue lo que el CELAM intentó en la III Conferencia General del Episcopado en Puebla. Pero alli se envidenció la subsistencia de los tres proyectos en la Iglesia latinoamericana y que la proposición del CELAM no ha logrado convencer del todo a los restauracionistas, ni descalificar a los liberadores. De alli, el tono tan dificilmente asimilable, pero a la vez, tan rico del documento final de la conferencia.

\section{Desarrollo sin secularización}

\subsection{Vuelta a lo sagrado}

En estos últimos años hay algunas novedades fundamentales. ${ }^{60} \mathrm{El}$ proyecto del desarrollo sin secularización ha sido relanzado sobre America Latina desde el Vaticano. El punto de partida es la preocupación muy legítima por el auge del secularismo que no sólo mina las bases de la religión, sino que a la larga, al privar al hombre de su misterio, disculpa su manipulación y mercantiliza las relaciones interpersonales y grupales. Se ha visto acertadamente que en un ambiente secularizado la injusticia fácilmente no aparece como tal, sino como efecto secundario de necesidades económicas. La "Relación final" del sínodo extraordinario de obispos con motivo de los 20 años de la clausura del Concilio Vaticano II subraya esta preocupación: "los signos de nuestro tiempo en algunos puntos no coinciden del todo con los que constituyeron las circunstancias del Concilio. Entre ellos hay que atender especialmente al fenómeno del secularismo (...) reducción de la visión integral del hombre, que no lleva a su verdadera liberación, sino a una nueva idolatría, a la esclavitud bajo ideologías, a la vida en estructuras de este mundo estrechas y frecuentemente opresivas." 61

Pero la distinción entre legílima secularidad y deformación secularista no se ha 
aplicado con igual rigor y consecuencia a la religión. La relación del sínodo que comenta los devastadores efectos del secularismo apunta esperanzadoramente: "existen también signos de una vuelta a lo sagrado" (id.). La observación es indudable. Pero llama la atención que no se discierna su significado. Porque existe sacralidad cristiana y sacralidad pagana. Para nosotros esta última es también una nueva (viejísima) idolatría. Muchos cristianos en los paises desarrollados piensan que el dilema está entre Dios y no Dios. Nosotros en América Latina creemos que hoy hay pocos ateos. Nuestra época en efecto está marcada por una vuelta a lo sagrado: en gran parte es una época fetichista.62 El poder está ritualizado y obliga a llevar su marca (Ap. 13,15-18) y a servirlo incondicionalmente. Es una hora en que se nos obliga compulsivamente a encuadramos. Tambien el sexo tiende a verse menos como una función humana, y más como fuente sagrada de vida que dernanda entrega y culto.

Así, pues, para los cristianos la religión, como el ,resto de las dimensiones humanas y más aún, es profundamente ambigua: es camino a lo sublime, pero también a lo mezquino, a lo sórdido y a lo más deshumanizador. Sin embargo, los profesionales de la religión tienden a olvidar esta ambivalencia insuperable y a colocarse a si mismos y a sus funciones en la misma esfera sagrada del misterio al que apuntan. De este modo, falta de sospecha y crítica intema, la religión tiende a absolutizarse. Y asf la correlación secularismo-injusticia busca resolverse unilateralmente por el lado de la religión: la resacralización traería necesariamente a la larga una mayor justicia.

\subsection{Resacralización y neoconservatismo}

Naturalmente que, más allá de las intenciones de sus factores, esta proposición resulta muy sugestiva para los neoconservadores. Sin ir más lejos Reagan se hace eco constantemente de ella, 63 sin que veamos ningún intento claro por parte de estos hombres de Iglesia por establecer un deslinde.

En este proyecto, el misterio cristiano, que es el amor misericordioso de Dios en nosotros, ${ }^{64}$ fácilmente se reinterpreta como un más allá recóndito, una emoción exquisita y un comportamiento fundamentalista. Se recae en la dicotomía entre almacuerpo, esta vida-la otra y lo sacral-lo profano. Este mundo, esta vida, este cuerpo se salvarían por su inserción en lo eterno, en lo eclesial, en lo del alma. Eso se lograrfa mediante prácticas específicas en lugares y tiempos especiales.

No se trata ya de intercambiarse creadoramente con el medio y transformarlo. Se trata por el contrario de salvarse de la dureza, la frialdad, el anonimato y la desintegración ambientales.

No es difícil adivinar la tentación que encierra este esquema en América Latina hoy. A los miembros de la clase alta les reafirma en su identidad y sentido de misión ancesurales (los que justificaron su nacimiento como clase desde el origen de la colonia) sin necesidad de conversión. A gente de los sectores medios la entrega a lo sacral significa un aumento de autocontrol y un ahorro de energfas que pueden canalizarse en orden al ascenso social. Para los jóvenes marginales supone la integración en un grupo con relevancia social; es dejar a la espalda el medio físico, 
las relaciones, las costumbres y hasta el lenguaje del barrio y pasar a un medio selecto y prestigioso. Ya el cristianismo no está ligado a la ardua tarea de la solidaridad, ahora se trata por el contrario de transformarse uno, de salir de ese mundo del desorden y la ignorancia y entrar en un ambiente en el que las contradicciones sociales parecen haberse evaporado.

\subsection{Razones de fondo}

El punto de apoyo coyuntural de este operativo resacralizador seria la reconocida vaciedad ambiental, la ausencia de símbolos, de pautas y lazos profundos, la falta de un proyecto societario capaz de despertar esperanzas sólidas en la colectividad. Si este mundo tiende a verse como irremediablemente profanado, entregado al juego brutal de la fuerza y la astucia, en algún lugar habrá que poner las ansias de dignidad y armonla.

Pero en América Latina este proyecto pretende además apropiarse, como legítimo exponente, de una fuerza mucho más permanente y profunda: la sacralidad que aún define a nuestro pueblo. El drama de la ilustración latinoamericana consistió, precisamente, en el divorcio que provocó entre élites y masa a causa, entre otras cosas, de su carácter secularizante. 65 Esta distancia ha pesado duramente sobre la historia republicana. Ahora, estas personas modemas y eficaces, se presentarian también como religiosas y, por lo tanto, confiables. Es el momento de cerrar esa brecha nefasta (sin el sacrificio supremo de acabar con la brecha económica). Las élites y el pueblo vuelven a rezar juntos. $Y$ las élites se comprometen a poner sus mejores esfuerzos en proseguir el duro trabajo del desarrollo con especial enfasis en la promoción popular, dentro, claro está, de las posibilidades de la situación.

\subsection{Los movimientos}

Este proyecto de desarrollo sin secularización se expresa sobre todo a través de movimientos. ${ }^{66}$ Grandes movimientos nacionales, latinoamericanos $y$, en definitiva, mundiales. Nada de comunidades de base. Esa dirección de abajo arriba es lente, dispersa, atomizada, anárquica. Por ahí no hay nada que buscar. Se requiere de un centro lúcido, fuerte, audaz: hombres de Dios providenciales que comprenden claramente las necesidades de la hora y son capaces de diseflar una estrategia completa para responder a ella. La salvación del medio sería, en este esquema, que el movimiento prevalezca en él imponiendo su identidad y su estilo. La institución eclesiástica, a través de esos grandes canales, es el alma de la sociedad. Para vivificarla, el centro envia directrices, materiales y símbolos a cada pais, localidad y ambiente.

Este esquema pide de algún modo entregar el alma; pero da a cambio seguridad, identidad, sentido de cuerpo y, por eso, sensación de fuerza y conciencia de misión.

A los laicos se les pide penetrar los ambientes, ser eficaces, marchar compactos. A los sacerdotes se les da un puesto rector, pero siempre que se limiten a ser los representantes de las directrices centrales. Los obispos no serian aqul "ordinarios de lugar," es decir, los que, incardinados en un lugar, tratan de leer en el los signos de los tiempos y a la luz del evangelio procuran que el pueblo a quien sirven tenga vida 
y vida en abundancia, comprometiéndose con ellos y luchando contra lo que amenace la vida de su pueblo. Como ya se sabe fundamentalmente lo que hay que hacer, a ellos toca coordinarlo, presidir las concentraciones, mantener la unidad como uniformidad. En el fondo la jerarqufa tiene por función "bajar la línea" desde los que la elaboran hasta el plano local, hasta las bases. El catolicismo sería así la diócesis del obispo de Roma Los demás serían portavoces.

\section{Uniformidad o catolicismo}

\subsection{El debate de nuestra época}

Hablando del cristianismo, el problema de nuestra época es el de la catolicidad; es decir, hoy se decide, tal vez por siglos, si el catolicismo va a quedar confinado en el mundo occidental, como su alma, o si, como lo quiso Jesús, va a llegar a ser un camino que concieme a todos, a cada pueblo según su cultura y sus expresiones religiosas.67 Hoy existen las bases materiales para el logro de la catolicidad. Existe sobre todo el anhelo movido por el espiritu de Jesús.

Este es el proyecto que late en la teología de la liberación. De ahí su potencial inspirador y las rápidas conexiones que se han entablado con movimientos cristianos africanos y asiáticos que enfatizan también la necesidad de constituir iglesias locales, que serán necesariamente iglesias populares. Hay que recalcar que en estos movimientos convergentes no hay ni asomo de tendencias cismáticas. Es algo que ni los más conservadores se han atrevido a reprochar porque de lo que se trata, por el contrario, es de regresar a pentecostés, acontecimiento fundacional en la Iglesia (Hch. 2) en el que la unidad de Espritu se expresó en la pluralidad de lenguas, lo que significa que, en la Iglesia, la uniformidad mata al Espíritu, que sólo puede expresarse en la variedad de culturas. Esta pluriformidad no entrafta, sin embargo, dispersión ni anarquía porque las iglesias periféricas, que tanto insisten en su autoexpresión, son también las que recalcan en la teoría y más aún en la práctica el retomo al evangelio, al único Jesús de Nazaret ${ }^{68}$ más allá de derechos canónicos y otras presiones derivadas, muy marcadas por la cultura occidental y por eso difícilmente universalizables.

\subsection{Constitución de la Iglesia latinoamericana y constitución de América Latina}

En América Latina este debate cristiano sobre la uniformidad o la catolicidad coincide con el debate histórico que tiene planteado el subcontinente. Si la Iglesia latinoamericana alcanza a definirse en la práctica como Iglesia popular latinoamericana toda la región estará en mejores condiciones para reconocer y realizar su genuinidad respecto de occidente. Tras la segunda guerra mundial eclosionó el proyecto modernizador que habla pugnado por expresarse entre nosotros desde los anos 30. La década de los 60 es la década del desarrollo entendido como occidentalización: la Alianza para el Progreso. Esa experiencia demostró la inviabilidad del proyecto. Pero ni el imperio ni las burguesfas tienen otro de recambio. 
Como apuntamos más arriba, la Iglesia latinoamericana se jugó en este proyecto y por eso hubo sectores en ella que pudieron trascenderlo desde dentro. A través de toda la historia de América Latina la Iglesia ha contribuido para bien y para mal a la aculturación del pueblo. También, desde el comienzo, en sus sectores más lúcidos y en el pueblo, el cristianismo ha obrado como fuerza de resistencia del núcleo éticomítico y de mestizaje fecundo. En buena medida la institución eclesiástica había dado la espalda al pueblo al proponerle un cristianismo criollo (es decir iberoamericano) cada vez más romanizado y finalmente puesto al día de las cristiandades modernas europeas. De ahí la acentuación de la distancia entre la institución eclesiástica y el pueblo, que los obispos venezolanos reconocen sin ambages: "nuestro pueblo no rechaza la Iglesia, la quiere, pero no se 'siente' Iglesia." ${ }^{9} \mathrm{El}$ pueblo no se siente Iglesia porque, a pesar de las declaraciones teológicas y dogmáticas, instilucionalmente no lo es. No lo es porque al estar la institución eclesiástica occidentalizada el pueblo no cabe en ella, sino mediante el blanqueo, es decir, la aculturación. De ahi que las personas del pueblo que pertenecen a ella, incluso en sus más allas esferas jerárquicas, hayan pasado a ser "de origen popular," pero separadas ya cultural y socialmente del pueblo.

\subsection{Teología de la liberación y latinoamericanización de la Iglesia}

El proyecto pastoral de liberación integral, como dijimos artiba, propone (y sobre todo está llevando a la práctica) devolver al pueblo cristiano sus derechos y para eso hacer una institución eclesiástica del propio pueblo. De ahí que el intercambio horizontal y abierto sea su base organizacional, más decisiva aún que los contenidos. Para poner un ejemplo bastante sintomático, en América Latina hay unos $250 \mathrm{mil}$ religiosos. El modelo propuesto para ellos por la teología de la liberación no puede ser más tradicional: María de Nazaret. ¿Dónde estaría la novedad? Se trataría de pasar de la Virgen (denominación genérica y, por lo tanto, proclive a proyectar en ella la imagen sublimada de la cultura dominante) como ejemplo de "vida interior" a María de Nazaret (una figura histórica única y, por lo tanto, ligada a unos rasgos bien característicos) como modelo no sólo de "vida interior," sino de una determinada concreción histórica: una mujer del pueblo consagrada a Dios en el seno del pueblo. Como se ve esta imagen no coincide con la figura tradicional de monja y requiere un proceso histórico creativo hasta transformar a la religiosa en una diferencia interior del propio pueblo. No es difícil vislumbrar la trascendencia cultural y social de este cambio. $Y$ hay que decir que el cambio se va dando de modo bastante armónico y no sólo a nivel de religiosos, sino incluso a nivel de obispos. Tal ha sido hasta cierto punto Proaño en Riobamba (Ecuador) y lo son en Brasil Pires y algunos más.

Cambiar de lugar social significa para la institución eclesiástica latinoamericana anudar con los fundadores 70 y desandar un camino que va a cumplir 5 siglos. La operación como se ve es radical. Porque a la larga la institución eclesíśstica no puede estar arriba y abajo. Una Iglesia desde el pueblo no significa una Iglesia de segunda, la división medieval de alto y bajo clero. No se quiere una pobre Iglesia, sino una Iglesia pobre. Desde los pobres se trala de asumir la globalidad social y cultural con 
todas sus complejidades. En un continente en el que la Iglesia conserva tanto peso, la proposición es verdaderamente revolucionaria.

\subsection{Folklore y aculturación}

Por eso el proyecto que comentamos arriba de desarrollo sin secularización pretende salir al paso de esta dirección. Para él la altemativa a la religión institucionalizada del pueblo es el fomento de la "religiosidad popular" expresada sobre todo a través de santuarios, peregrinaciones, concentraciones masivas en las que el pueblo se unimisme, pero no tenga ocasión de decir su palabra, sino de asentir a la palabra de los lideres que lo representan institucionalmente. Este proyecto insiste en la minoridad del pueblo y por eso en la necesidad de preservarlo de los que pueden desviarlo y darle con pedagogía alimentos que él pueda digerir: catecismos simples, sacramentos y devociones. Hay que invitarlo a rezar, pero no a discutir ni a tomar la palabra. Más bien hay que darle directrices, que él acepta con sumisión. La evangelización, entendida en el fondo como romanización, durará siglos como dưo 10 la de Europa, pero no hay más camino que perseverar en el camino marcado. Claro que hay que aceptar las lenguas y los elementos del folklore; pero en lo fundamental la adaptación ha de ser la de la gente a la propuesta evangelizadora. América Latina se encuentra a más de medio camino; por su peso numérico y su creciente conciencia, en ella se juega en estas décadas la suerte del cristanismo. Si se acierta en el camino, luego entrarán por él Africa y Asia. Por eso es importante no ceder. De ahí el recelo insuperable hacia las comunidades de base y hacia la insistencia del proyecto de la teología de la liberación en el afianzamiento de un flujo comunicacional horizontal y abierto en la Iglesia.

\section{Elementos para un pronóstlco}

¿Cabe hacer algún pronóstico? Yo no me siento en condiciones de hacerlo. No me cuento entre quienes declaran paladinamente que el camino recorrido por la teologfa de la liberación es irreversible y menos aún entre los que avalan esa convicción con argumentos teológicos.

En primer lugar, creo que la variable más decisiva escapa a la institución eclesiástica. Si la crisis actual se sigue procesando en la línea de compactación social, creciente ideologización y control cada vez más férreo de las masas sobre las que se carga la cuota más pesada de las dificultades y del costo social necesario para superarlas será muy difícil que la institución eclesiástica no asuma más o menos este modelo trascendentalizado, insistiendo en la unidad basada en la disciplina y en el acatamiento a una jerarquía cada vez más separada del pueblo de Dios. Puede ser que resistan minorías importantes, incluso segmentos enteros de la institución, como sería el caso hasta hoy de la CLAR (Confederación Latinoamericana de Religiosos) y de la CNBB (Conferencia Nacional de Obispos Brasilefios). Pero en estas circunstancias no es fácil suponer que el grueso de la institución eclesiástica fuera más allá de una contradicción interna en el bloque de poder.

Las variables intraeclesiásticas serian las siguientes. La primera y principal, si es 
correcta la apreciación de la teologla de la liberación de que se inicia una era marcada por el surgimiento del pueblo como sujeto histórico. Naturalmente que esta afirmación debe ser fuertemente matizada; pero, si ocurre, la capacidad del cristianismo de resistir ante una situación económica, política y cultural adversa es bastante apreciable. La segunda tiene que ver con la vida religiosa: el nacimiento de América Latina está ligado a ella ya que sin su acción evangelizadora no serfa pensable la cristianización de los indígenas. Religiosos son las figuras epónimas de los fundadores del cristianismo latinoamericano. Pero la vida religiosa entró en crisis en el siglo XVIII, en el XIX fue barrida de América Latina y sólo a fin de ese siglo comenzó a reimplantarse. Actualmente esta en plena floración, tomando conciencia de su ser y su misión y tratando de anudar con los comienzos latinoamericanos. Si esa creatividad perdura y no es extroyectada o severamente podada puede ser un rico fermento y una plataforma en extremo versátil para implantar el proyecto liberador, aun en circunstancias adversas. La tercera tiene que ver con la posibilidad de que el episcopado latinoamericano, que en los afios 60 empezó a tomar conciencia de su identidad latinoamericana, vuelva a asumir ese compromiso primordial y se afiance en él. Aquí el obstáculo principal sería la insistencia de algunas instancias vaticanas en orden a la romanización integral proponiendo como tarea principal cerrar filas con el Papa (como si el Papa fuera atacado por alguien en América Latina) y desviándose de la tarea propiamente pastoral de dar vida al pueblo con sus propias vidas. La cuarta variable es, desde luego, la capacidad de expansión que tenga el proyecto de desarrollo sin secularización. Para ello cuenta, además de sus recursos propios, con los medios de comunicación y otros recursos del orden establecido.

El proyecto de la teologia de liberación ha recorrido bastante camino, pero las direcciones contrapuestas cuentan con muchos recursos. Yo diría que aún no se vislumbra el desenlace. Pero que, sea cual sea, lo que estamos viviendo ya merece la pena. Lo demás, Dios dirá.

A lo mejor lo que resulta es la coexistencia dentro de un pluralismo incomponible, hasta que el tiempo vaya decantando las opciones. Mucho tendrfamos que aprender todos para que esto fuera posible. Para ml serla sin duda lo mejor. Que fue lo que paso al principio (Hch. 5,34-39).

\section{NOTAS}

1. P. Trigo, "Un compromiro hirtorico," SIC, 1979, 413, 114-118.

2. Puabla, 450.

3. B. Dussel, Historia genaral de la Jglesia en América Latina, J/1, Salamenca: S'gueme, 1973, 205 716. L. Lopeteguie, Historia da la Iglesia en la Ambrica espatiola. Insroducción general. Madrid: BAC, 1965, 3-208. H. Prien, La historio del cristionismo en Amdrica Latina, Salamance: SIgueme, 1985, 73-386.

4. Prien, o.c., 387-848. F.B. Pike, en Nuew historia de la Iglesia, Madrid: Ediciones Cristiandad, 1984, V. 316-354. J.L Segundo, Acción passoral lasinoamericana. Buenos Aires: Búsquede, 1972, $27-44$.

5. Acta et Decreta Concilii Plenarii Americae Latinae. Romae: Typis Vaticanis, MDCCCC.

6. Pio XI. Ver, por ejernplo, en non Abbiamo bisogno, 29 de junio de 1931, No. 7.

7. Medellan, 1980, 21, 118-150. 
8. Pane el pirnfo que vigue ver J.L Segundo l.c

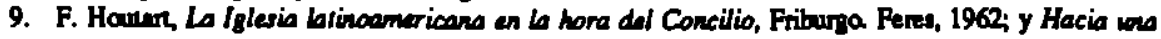
seologe del desarrollo. Friburgo: Feres, 1963, R. Pin, Elementos pare uno sociologe del

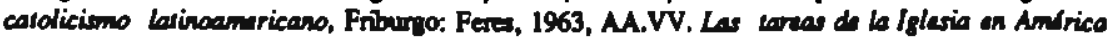

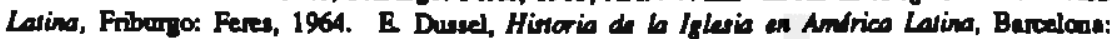
Nove Terr, 1972, 177-201. G. Guiterne, La pastoral de la Iglesia en Amfrica Latina, Montevideo: MIEC-JECI, 1968, 23-26, 36-41. I. Congreso Catsico Intenamericaro pare al desarrollo integral del

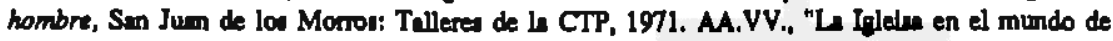
hoy," Mensoje, 1966, 153.

10. Ocho grandes mersajes, Madrid: BAC, 1977, 13-56.

11. Ideario, Barcalana: Ariel, 1970, 270.

12. Buenos Aira: Edirorial Carlos Lohle, 1966.

13. O.c., 695 .

14. O.c., 696.

15. Ideario, 54.

16. O.e., 283.

17. R. Calden, Especificidad de lo democracia crimtiana, Cancas: Caronh, 1972, 65.

18. Ideario, 75-76.

19. Vols. I-V, Buenou Aires: Edicorinl Carlos Lohle, 1969 a 1972

20. "Si me dirijo a los hombres para hablarle y actuar entre ellos, en el primer plano de actividad, el espiriturl, aparezoo ante ellos en cuanto cristiano y, por lo trinto implico a la Ielesin de Cristo; en el regundo plano, en el tempond, no sctio en cuanto cristiano, pero debo rening en criatimo, comprometitndame \& ml mirmo, no a la Iglesin, pero comprometiendome entersmente yo (que) lengo voceción de infundir al mundo, alle donde me encuentre, une envis cristinn" (O.c., 221).

21. Deparremento de Acción Social. Documentos CELAM, No. 1, Bogoth, 1967, 21.

22. Bases, Buenos Aires: Plu Ulun, 1974, Ver P. Trigo, "Proyectos hisibricos en America Latins," Anthropas, 1983, 6, 49-56.

23. J. Camblin, Tiempo de accion, Limi: CEP, 1986, 342-348.

24. Pablo VI, "Dircurno a ls ONU," 5 de octubre de 1965. Lo cin Junn Pablo II en au discurso inougurel de Puebla, III, 3.

25. La Iglesia aste al muado modemo en América Latina. Signas de renovacion, Lima: CEP, 1969, 47. 66.

26. Secraniedo Genenl del CELAM, La Iglesia en la actual iransformación de Andrico Latina a la luz del Concilio - Conclusiones, Bogor, 1968. Ver wobre todo el documento robre la par, 63-76.

27. Ideario, 137.

28. Manifiesto al servicio del personalismo y cristianismo, Mednid: Taunu, 1965.

29. Desarrollo sin capitalismo; hacia un mundo comunicario, Caraces: Nuevo Orden, 1964.

30. Ocho grandes mensajes, Medrid: BAC, 317-365.

31. Cristianismo y revolución, Méico: En, 1972.

32. Pan Venezvela, por ejemplo, ver CERPE, La aducación cosolico en Venaruale (1884-1986), Cencer, 1986, 18-52.

33. Medallin, 2, 16.

34. A. Benton, Fe y Alogrb en el pensamiento dal Padro Jast Morla Volas, "Fe y Alegrín enpiezn donde vermina el afalto, dende se acabe el cemento, donde no llege el ague posable," Ceraen, 1981, 29.

35. J. Sobrino, Reswrección de la verdadera Iglesia, Saniunder. Sul Terme, 1981, 118. A eate llevane muturnente, Sobrino lo llema "primera ecksinlided" (o.e., 114).

36. L Boff, Eclesiogénesis, Suntender. Sal Terme, 1979, 9-73.

37. Pueble define el trmino en el No. 450. Le Iglesin que nace del (en el) pueblo el el útulo de dor Libros latinoumericanos, Salmanca: SIgueme, 1979, y Bogoti: Indo American Preus Service, 1979. Ver umbien G. Gutierrez, La fuena históriea de los pobres, Lims: CEP, 1979, 117127. R. Múfioz, La Iglesia del pueblo, Lims: CEP, 1983.

38. P. Trigo, "LDactrine social de in Igleain?" Nueva Sociedad, 1978, 36, 35-44. 
39. Ideario, 56.

40. Utilizo el turmino teologin de ln libención en el sentido amplio en que lo une lo Innurucción vaticme sobre in mieme, como "movimiento teologico y pentonl" SIC, 1984, 468, 375.

41. Uns presenterion auscinte y procius on G. Guliemez, La vendad os hard libres, Lima: CEP, 1986, 11 30. Un libro enedllo y priction, L. y C. Boff, Como se hace teologia de la libenacion, Madrid: Paulines, 1986.

42. G. Guntrez, Teologle dasede al reverso de b historia, Limn: CFP, 1971, 33. J. Sobrino, Reswrección de b verdedera Iglesia, 109, 175. I Ellnaurh, "Loe pobrea lugar tealogico' en America Latine," en Conversión de la Iglesio al reino de Dios, Suntunder. Sil Terme, 1984, 153178. J. I Gonzilez Faus, "Los pobres cano lugar teologion," Revisea Latinoamericana de Teologin, $1984,3,275-308$.

43. X. Quinzt, "Leer hoy los aignos de los tiempos," Razón y fe, 1985, 1046, 377-386. Concilio Valiano II, GS. 4, 11, 44; PO 9; AA, 14; UR. 4. "Relncí́n final" del slnodo de lou obispos de 1985, II A) 1, D) 1,7. J. Comblin, o.e. G. Gutiere, Beber en su propio pozo, Lims: CEP, 1983, 36-44. Id: TL 24.

44. J. L Segundo, Liberacion da la teologio, Buenoo Aires: Editorial Carlos Lohle, 1975, 94.

45. AA.VV. "Espiritunlided de le libencion," Chritus, 1979-1980, 55-95, 529-530. G. Gutífrez, Beber...; J. Sobrino, Liberación con esperitu, Sanunder. Sal Terree, 1985. S. Galilea, El camino de la espiritualidad, Bogots: Pauline, 1982. T. Cabestrero, No las separb la muerte, Santander. Sal Terre, 1985.

46. Puebla, 31-39.

17. G. Gutitrrez, Teologle y ciencias sociales," en La verdad..., 75-112

48. Un documento histórico sobre el tema es la carn pastonl de los obispos salvadorefios Romero y Rivern, La Iglesia y las organizaciones polf́icas populares, an SIC, 1979, 411, 4 ss.

49. Puebla, 263-263.

50. De le copiosisime bibliografte, existente, ademí de los libros citados en las notes 36 y 37 y de los numerocon de Marina y un equipo, recogemos los siguientes: L Boff, "La comunidad eclesial de base: lo minino de lo minimo," en Iglesia: carima y poder, Sumunder. Sal Terrae, 1982, 197-217. C. Boff, CEB y prdeticas de liberacion, Bogor: Indo Amerian Pres Service, 1981. Fny Bento, Lo que son las CEB, Bogoll Indo American Press Service, 1981. A Zenteno, Un camino de humildad y esperanea, Merico; CAM, 1983, P. Trigo, "Comunidades cristianas de base en Veneziele," SIC, 1982, 449, 412-416.

51. El teme es inabarable. Algunos nombres importantes aerian, T. Kudo, D. Irarrasabal, J. L. Gonzillez, M. Maral (en Peri), F.C. Roli, R. Azzi, P.A. Ribeiro de Oliverie (en Brasil), L. Gere (en Argentina)... Un modelo de repenorio bibliográrico seria el de J.L. Gonzalez y P. M. v. Ranzelen, Religiasidad popular en el Pení, Limn: CEP, 1984. Un ejercicio cenerelo de dillogo esclarecedor an Bebar... III, "Libres pare amar," 137-202 P. Trigo, "Teologln de la libención y culturn," SIC, 1984, $462 \quad 7478$.

52. La luche idealogica tiene muchos frenter y varin aegún las coyunturas, los paises y le ubieación de los teólogos en le príctice pastonl de las iglesia. De ahl que los tertigos o los "liberados" sean los que cuenten con mas libersed pare ejercerle Entre los primeros habrie que mencionar a J.L Segundo (ver el tomo I do su critologh titulado "Fe e ideologla," Madrid: Edicienes Cristinndad, 1982), entre los eegundos a H. Assmenn, F. Hinkelemmert y E. Dussel. Cito como ejemplo algurns obras de Hinkelemener, Las armas ideologicas de la muerte, San Jose: DEI 1981; Crática de la razon usopica, San Jost: DEI, 1984; "El dios montal: Lucifer y la Bestia," en Capitalismo: violencia y antivida, San Jost: DEX, 1978, L, 199-313; "La polltica del mercado lothl, su reologizacín y nuestn respuests, "Pasos-DE, 1985, 1.

53. Ver por ejemplo J. Sobrino, Reswrección..., 210-242. A. Quiroz, Eclesiología en lo reologí de la liberación, Salemanca: SIgueme, 1983, 250-268.

54. Es un tema clave Algunas aproximaciones, J. L Segundo, Teología de la liberación, Madrid: Ediciones Cristiended, 1985, 138-174; AA.VV., Capisalismo: violencia y anti-vida, I y II. especialmente II. 259-275. 
55. Medellk, 2,15.

56. J. Comblin, "L guem y ln palebre," en Antropologia cristiana, Madrid: Pauline, 1985, 204-223. Helder Chman cerin entre nosotroe pionero de ente postun Espiral de violencia, Salmanca: Sigueme 1970.

57. Jum Pablo II he enfuizado an multioud de ocariones que el tnbajo es la fuente de valorizacion y. por lo unto, de propieded, ve Laborem Excercens, 12-14.

58. J. Comblin, Tiempo de acción, 430-456. P. Trigo, "Marrious y cristimnos," SIC, 1976, 389, 414-416. Lo autmcial del sporte marrista a in teologin de in libencita ererta recogido y uumido an Libertatis Conseientiae, 83.

59. AA.VV., La lucho de las dioses, Sen Jost: DEI, 1980.

60. P. Trigo, "Dos modelos de organizacion eclesirstica," SIC, 19 1983, 453, 109-112.

61. SIC, $1986,481,42$.

62. Rerulu intamírio el planteamiento de $\mathrm{H}$. Cor, La religión en lo ciudad secular, Santander. Sal Terre, 1985. Sobre el ferichismo ver ls nots 52, en especinl Hinkelammert. Ver adembs, E. Dussel, "El concepto de felichimo en el penemiento de Mara, "Critianismo y sociedad, 1985, 85, 7.59.

63. A.M. Ezcuma, El Vaficaro y la edministración Reagan, Mexico: Nuevornar, 1983. M. Sweeney, "Reagan y la religion," SIC, 1986, 485, 225-227. Id. SIC, 1986, 486, 273-275; 1986, 487, 306309.

64. "Relación final," del afnodo o.c.

65. P. Trigo, "Teología de le liberación y cultura," Revista Latinoamericana de Teología, 1985, 4, 8389.

66. J. Comblin, "Os 'movimentos' e a pastonal hino-americana," REB, 1983, 43, 227-262.

67. K. Rahner, "Una interpreación teologia a fondo del Concilio Vaticano II." Razón y fe, 1979, 980 981, 983-995.

68. L. Boff, "Une visión altemativa: la Iglesin sacamento del Esplritu," en Iglesia: carisma y pader, 227-243; J. Sobrino, Cristologla desde América Latino, Mexico: CRT, 1977, 1-13, 297-338. A. Quiroz, 0.c., $210-242$

69. CEV Panorama eclesial. Iglesia-Venezuela, 1977, 17, 97.

70. Puebla, 7-8. 